\title{
Framework for effective additive manufacturing education: a case study of South African universities
}

\author{
Micheal Omotayo Alabi \\ Faculty of Engineering, Development and Management Engineering, North-West University, Potchefstroom, South Africa \\ Deon Fohan de Beer \\ Department of Innovation and Commercialization of Additive Manufacturing, Central University of Technology, Bloemfontein, South Africa \\ Harry Wichers \\ Faculty of Engineering, School of Mechanical Engineering, North-West University, Potchefstroom, South Africa, and \\ Cornelius P. Kloppers \\ Faculty of Engineering, School of Mechanical Engineering, North-West University - Potchefstroom Campus, Potchefstroom, South Africa
}

\begin{abstract}
Purpose - In this era of Fourth Industrial Revolution, also known as Industry 4.0, additive manufacturing (AM) has been recognized as one of the nine technologies of Industry 4.0 that will revolutionize different sectors (such as manufacturing and industrial production). Therefore, this study aims to focus on "Additive Manufacturing Education" and the primary aim of this study is to investigate the impacts of AM technology at selected South African universities and develop a proposed framework for effective AM education using South African universities as the case study.

Design/methodology/approach - Quantitative research approach was used in this study, that is, a survey (questionnaire) was designed specifically to investigate the impacts of the existing AM technology/education and the facilities at the selected South African universities. The survey was distributed to several students (undergraduate and postgraduate) and the academic staffs within the selected universities. The questionnaire contained structured questions based on five factors/variables and followed by two open-ended questions. The data were collected and analyzed using statistical tools and were interpreted accordingly (i.e. both the closed and open-ended questions). The hypotheses were stated, tested and accepted. In conclusion, the framework for AM education at the universities was developed.

Findings - Based on different literature reviewed on "framework for AM technology and education", there is no specific framework that centers on AM education and this makes it difficult to find an existing framework for AM education to serve as a landscape to determine the new framework for AM education at the universities. Therefore, the results from this study made a significant contribution to the body of knowledge in AM, most especially in the area of education. The significant positive responses from the respondents have shown that the existing AM in-house facilities at the selected South African universities is promoting AM education and research activities. This study also shows that a number of students at the South African universities have access to AM/3D printing lab for design and research purposes. Furthermore, the findings show that the inclusion of AM education in the curriculum of both the science and engineering education is South Africa will bring very positive results. The introduction of a postgraduate degree in AM such as MSc or MEng in AM will greatly benefit the South African universities and different industries because it will increase the number of AM experts and professionals. Through literature review, this study was able to identify five factors (which includes subfactors) that are suitable for the development of a framework for AM education, and this framework is expected to serve as base-line or building block for other universities globally to build/develop their AM journey.

Research limitations/implications - The survey was distributed to 200 participants and 130 completed questionnaires were returned. The target audience for the survey was mainly university students (both undergraduate and postgraduate) and the academics who have access to AM machines or have used the AM/3D printing lab/facilities on their campuses for both academic and research purposes. Therefore, one of the limitations of the survey is the limited sample size; however, the sample size for this survey is considered suitable for this type of research and would allow generalization of the findings. Nevertheless, future research on this study should use larger sample size for purpose of results generalization. In addition, this study is limited to quantitative research methodology; future study should include qualitative research method. Irrespective of any existing or developed framework, there is always a need to further improve the existing framework, and therefore, the proposed framework for AM education in this study contained only five factors/variables and future should include some other factors (AM commercialization, AM continuous Improvement, etc.) to further enhance the framework.
\end{abstract}

The current issue and full text archive of this journal is available on Emerald Insight at: www.emeraldinsight.com/1355-2546.htm

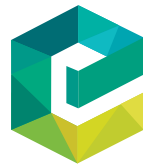

Rapid Prototyping Journal

(C) Emerald Publishing Limited [ISSN 1355-2546] [DOI 10.1108/RPJ-02-2019-0041]

Received 21 February 2019

Revised 11 August 2019

Accepted 13 November 2019 
Practical implications - This study provides the readers and researchers within the STEM education, industry or engineering education/educators to see the importance of the inclusion of AM in the university curriculum for both undergraduate and postgraduate degrees. More so, this study serves as a roadmap for AM initiative at the universities and provides necessary factors to be considered when the universities are considering or embarking on AM education/research journey at their universities. It also serves as a guideline or platform for various investors or individual organization to see the need to invest in AM education.

Originality/value - The contribution of this study towards the existing body of knowledge in AM technology, specifically "AM education research" is in the form of proposed framework for AM education at the universities which would allow the government sectors/industry/department/bodies and key players in AM in South Africa and globally to see the need to invest significantly towards the advancement of AM technology, education and research activities at various universities.

Keywords 3D printing, Additive manufacturing, Technology, Industrial revolution, Additive manufacturing education, South African universities, STEM education, Framework

Paper type Case study

\section{Introduction}

According to Wohlers (2010), additive manufacturing (AM) is the official industry standard term (ASTM F2792) for all applications of the technology. AM is also known as $3 \mathrm{D}$ printing technology and it is defined "as the process of joining materials to make objects from 3 D model data, and it is usually layer upon layer, as opposed to subtractive manufacturing methodologies". $\mathrm{AM}$ has been identified as a twenty-first century emerging technology and is becoming popular within the academia and several industries globally. Some of the characteristics of AM is that, it reduces waste material, brings down labor costs, speeds up the development and test phase, and product customization and ability to make complex metal parts (CSIRO, 2015) and also, AM helps to reduce mistakes and delays to a minimum and produce winning products (Wohlers Associates, Inc, 2011).

South Africa is one of the active countries on the Africa continent promoting AM technology, education and research both in the academia and industry. It is predicted that AM technology will play a significant and game-changing role in the Fourth Industrial Revolution, 4IR, also known as "Industry 4.0". AM technology has been active in South Africa for past 26 years and is expected to re-industrialise the economy of South Africa (NSTF, 2016). In March 2016, during the National Science and Technology forum (NSTF), a discussion forum for Science. Engineering. Technology for SocioEconomic Growth in South Africa; the panel discussions focused on AM in South Africa and it was stated that the AM sector in South Africa is being led by higher learning institutions and science councils; and the two leading institutions are Central University of Technology (CUT) and Vaal University of Technology (VUT) where products are being made on a regular basis for various sectors. CUT focuses primarily on serving the "medical industry" while VUT serves the "tooling and casting industries". Moreover, the NorthWest University and Stellenbosch University are also part of the AM players in South African universities (NSTF, 2016). For a successful AM education and research journey in South Africa, industry-led research is essential (NSTF, 2016).

In 2000, the Rapid Product Development Association of South Africa (RAPDASA) was officially launched and since then, the RAPDASA serves as the representative body of the technical service providers and researchers in the product development of AM field in South Africa, and also raising awareness through annual conference and international ties such as Global Alliance of Rapid Prototyping Associations (Du Preez et al., 2016; Kunniger, 2015). To promote AM technology, education and research activities, South Africa AM roadmap was developed with different four focus areas (i.e. qualified AM parts for medical and aerospace, AM for impact in traditional manufacturing sectors, new AM materials and technologies and SMME development). The SA AM roadmap was designed with an intention to guide AM development and key players to identify economic opportunities, address technology gaps, focusing on developmental programs, informing investment decisions and to enable local SAs' companies and industry sectors to become global leaders in selected areas of AM (Du Preez and De Beer, 2015). The next few paragraphs in this introductory section states the reasons why this study (i.e. development of framework for AM education) is necessary in the South African institutions context and discusses the problem statement and research questions this study is set to answer/address.

According to Krassenstein (2014) one clear reasons why AM technology has been quite slow in making its impact in the educational institution is simply because of the "lack of knowledge of the technology by the academia, students and the decision makers in charge of AM technology". In South Africa, education has been identified as one of the main priorities to ensure successful adoption of AM techno logy during a stakeholder's workshop in 2013 and the comprises of 105 people from industry, government, Higher Education Institutions (HEI), $3 \mathrm{D}$ printing service providers and $\mathrm{R} \& \mathrm{D}$ institutes. (Du Preez et al., 2016). Du Preez et al. (2016) further explain that "as the AM technology grows in South Africa, the need for educated personnel in the field is becoming more apparent". In the same vein, Akinlabi (2016) mentioned the position of AM technology at South African universities at the " $14^{\text {th }}$ Light-based Technologies Innovation Forum" during the presentation entitled "Additive Manufacturing: Advances in Academia and Teaching" and stated that:

South Africa Additive Manufacturing in the academia and undergraduate teaching is still at an infancy stage and $3 \mathrm{D}$ printing technology is a global technology with a lot of relevance in the industry and it is a multidisciplinary

Furthermore, Akinlabi (2016) supports Du Preez et al. (2016) point of view on the educational aspect AM technology in SA and emphasizes on:

The need for a group that will act as crusaders to champion its inclusion AM technology/education in the curriculum of the relevant courses for the country to fully reap from its enormous benefits of the technology 
From an industrial expert perspective, Gungor Kara, the Director of Global Application and Consulting at EOS also identifies education as an important element to advance AM technology (Davies, 2017), as stated below:

[Education is] the key element to access the full potential of the additive manufacturing technology. The situation in the past, the educational programmes [have been] connected to universities, and the professional training for experienced engineers in companies was missing

The rationale for this study or the research problem for this study is that:

As several manufacturing and industrial sectors are adopting AM technologies in South Africa, there is a need for more university graduates, most especially in science and engineering with fundamental or in-depth knowledge of AM technology to work with the emerging AM sectors or 3D printing service bureau in South Africa. It is very important to develop an effective framework for AM education for South African universities that will further promote AM education among students, academia and industry's professionals

A research question is the fundamental core of a research project, study or review of literature (Biddix, 2009). Therefore, to achieve the aim and objectives of this study, this study seeks to answer one main research question and two sub-research questions. The main research question is as follows:

RQ1. Is there an effective framework for $\mathrm{AM}$ education at South African universities to further promote AM education and research activities in the field?

The sub-research questions are as follows:

RQ1a. What is the perception of students and academics towards the inclusion of AM education/course in science and engineering curriculum at South Africa universities?

$R Q 1 b$. How are the key factors/variables in the development of a framework for effective AM education derived or identified?

\subsection{Significance of the study within the South African universities context}

Specifically, there is a need to briefly discuss the significance of this study within the South African universities' context. As earlier mentioned, South African is an active and prominent country in the applications and advancement of AM technologies for past 26 years in both the academia and industry when compared to other countries on the African continent. The authors of this paper recently published a publication entitled "Applications of Additive Manufacturing at Selected South African Universities: Promoting Additive Manufacturing Education" (AME) (Alabi et al., 2019). This study presents details review of the significant progress of AM technology in South Africa dated back to 1991 and various applications of AM technology among the selected South African universities (Central University of Technology, CUT; Vaal University of Technology, VUT; North-West University, NWU and Stellenbosch University, SU). These four universities are the major universities with strong presence of Additive Manufacturing Lab, AM technologies facilities (both entry-level 3 D printers and Industrial High-end Additive Manufacturing Machines), AM research group and progressive AM research activities are being carried. In 2012, CUT was awarded a SA Research Chair in Medical Product Development using AM technology through the grant from DST. In 2018, the same university became SA Research Chair in Innovation and Commercialization of AM technology. The advances in AM journey in South Africa has been tremendous in different ways, for instance, a research and innovation support program in AM of qualified titanium medical implants and aerospace components and polymer AM and design for AM (DfAM) was established called "the Collaborative Programme for AM (CPAM) with the aim to advance research and development in AM technology which is also fully funded by DST (Williams, 2016).

Alabi et al. (2019) study also mentioned the numerous investments of South African government through the Department of Science and Technology (DST) and National Research Funding and other various funding bodies such as Industrial Development Corporation (IDC) and Technology Innovation Agency (TIA). In 2015, the South African Department of Science and Technology approved the development of South African National AM Roadmap (Du Preez and De Beer, 2015) and In 2016, DST and Council for Scientific and Industrial Research developed a "South African Additive Manufacturing Strategy" and the aim of the strategy is to assist in "identifying future addressable market opportunities and products in which AM technology development is required to position South Africa as a competitor in the global market" (Du Preez et al., 2016). As part of the AM journey and success, the South African researchers embarked on a journey to build the world largest and fastest state-of-the-art AM machine that would be able to $3 \mathrm{D}$-print metal parts using a powder bed fusion method and the project was called "Aeroswift" and launched in 2011 in collaboration with an aviation manufacturing solutions provider called (Aerosud) and the South African Council for Scientific and Industrial Research (CSIR) with the funding from the DST (Oberholzer, 2018; Scott, 2017). All the government investment on AM technologies in has imbued South Africa with specific state-ofthe-art capabilities, positioning the country to participate in sub-sectors with high growth potential in AM on a world scale (Williams, 2016).

Despite the huge investments of the SA government through DST and various involvements of selected South African universities in AM technologies, education and research activities. At the moment of writing this paper, there is no specific framework for AME at the South African university or AM education curriculum or its inclusion in the various curriculum of STEM programmes such as engineering and science degree. More so, there is no postgraduate degree (MSc) program tailored specifically towards AM technology. Therefore, this study is very significance to South Africa universities and the AM industry; and this study is set to investigate the impacts of the current $\mathrm{AM}$ education and research activities at SAs' universities and to develop an effective framework for $A M$ education and this proposed framework can be adopted globally at any university trying to embark on AM journey within the university context.

\section{Literature review}

AM technologies are still at an infant stage and to reap the full potential of this technology, its inclusion in the educational curriculum is very crucial. Through an extensive literature 
review, it was identified that there is no specific framework for $\mathrm{AM}$ education at the universities globally. As part of South African AM Strategy which is to ensure AM education at different educational levels, the development of a short, medium and long-term educational framework for AM was identified as one of the essential measures to achieve this issue (Du Preez et al., 2016). In this section of this paper, review of different studies as relating to $\mathrm{AM}$ education and its advancement within the universities system is presented. Furthermore, to effectively develop a new framework for AM education, there is a need to review or investigate various existing framework within the context of AM technology. However, the majority of the existing frameworks for $\mathrm{AM}$ technology found in literature is not necessarily in the educational context but would be used to determine the educational strategy or served as a landscape or building block to develop the newly proposed framework for AM education South African universities case study.

\subsection{Review of related studies on framework for additive manufacturing technologies}

Introduction of $\mathrm{AM} / 3 \mathrm{D}$ printing technology into the educational system is being referred to as AME. A framework for teaching basic AM technology was developed to enable rapid innovation using Massachusetts Institute of Technology (MIT) as the case study (Go and Hart, 2016). The approach presented in Go and Hart (2016) framework was for teaching basic AM technology at both advanced undergraduate and graduate level. The teaching method is in the form of 14 -weeks course which provides the students with the opportunity to use entry-level 3 D printers. The framework centers on developing a curriculum for teaching basic AM course at the university, which is just an aspect of AM educational framework. (Go and Hart, 2016).

Globally, due to little engineering graduates with $\mathrm{AM} / 3 \mathrm{D}$ printing knowledge; Swarup et al. (2018) studies aimed to encourage and enables students to build $3 \mathrm{D}$ printers and increase the adoption rate for AM technologies within the educational institution. In this study, the approach adopted to develop framework is expected to provide engineering graduates with hands-on-experience that will allows them to turn their innovative ideas into reality (Swarup et al., 2018). As a result of this, Swarup et al. (2018) developed an innovative AM ecosystem training framework that is capable of accelerating the adoption of $\mathrm{AM} / 3 \mathrm{D}$ printing technologies - a case study of Dayalbagh Educational Institute. The proposed framework in this study provides the students with potential platform to familiarize themselves with $3 \mathrm{D}$ printing production process and gain hands-on experience using open access technology, which is coupled with the understanding and application of relevant design skills (Swarup et al., 2018). The teaching platform enables the students to understand how the entire system is integrated, that is, the software, $3 \mathrm{D}$ models, $3 \mathrm{D}$ printing system, $3 \mathrm{D}$ printing software and hardware. However, few studies address framework for AM technology/ implementation in areas such as: mass customization, supply chain management, process monitoring, conceptual design, quality management, medical devices, etc. as identified in these articles (Mellor, 2014; Handal, 2017; Deradjat and Minshall, 2015; Pradel et al., 2018; Panesar et al., 2015; Cummings et al.,
2017; Togwe et al., 2018; and Williams et al., 2011) and further elaborated in the next few paragraphs of this section.

Mellor (2014) develops a "framework for AM implementation" which focuses mainly on the AM implementation processes. This study addresses:

The need for existing and potential future AM project managers to have an implementation framework to guide their efforts in adopting the new and potentially disruptive technology class to produce high value products and generate new business opportunities

The study develops a conceptual framework for AM implementation which is expected to be driven by both the external force and internal strategy. The proposed framework for AM implementation would be controlled by five factors (i.e. strategic factors, technological factors, organizational factors, operational factors and supply chain factors) as shown in Figure 1. Mellor (2014) study provides a very good insight into various challenges facing the AM implementation processes.

Deradjat and Minshall (2015) study identifies the limitations of Mellor (2014) study, which uses single case study. Deradjat and Minshall (2015)identifies a great potential for AM to influence Rapid Manufacturing (RM) and Mass Customization (MC) and noticed the gap around the topic of MC using AM technology and the need to investigate how AM could facilitate mass customization. The study investigates "how AM technology is being implemented by companies when it comes to mass customization production from technical, economic and business management perspective". This study uses literature review approach to identify four factors which was considered suitable to influence the AM implementation in the context of Mass Customization and these four factors includes (Technological factors, Operational factors, Organization factors and Internal/ external factors) as presented in Figure 2 (Deradjat and Minshall, 2015). This study makes a significant contribution to the literature gaps in the research areas of RM, MC and advanced manufacturing technology (AMT) implementation frameworks and provides relevant insights into more case studies and areas to be investigated in future studies; such case studies include medical, dental and surgical implants. However, this study made emphases on the significance of the technological factors and portray all the four factors as independent variables. One limitation of the study is that it does not include the implementation processes.

Deradjat and Minshall(2017) recognized the shortcoming of the previous study (Deradjat and Minshall, 2015; Mellor, 2014) and proceeded on another study and proposed a framework for rapid manufacturing implementation of $\mathrm{MC}$ using dental industry as the case study and identifies relevant factors for the AM process implementation. This study answered the research question "How do companies implement RM for MC in the dental industry". The dental industry was used as the case study because they were recognized as one of the major users of AM technologies. A framework for RM implementation for MC in dental industry was developed and five factors were considered as shown in Figure 3. The five factors considered are (Corporate strategy, Technological, Operational, Organizational and External factors) as interdependence variables. More so, this study includes the implementation process phases which were divided into three categories (pre-installation, installation and 
Figure 1 Framework for AM implementation as proposed by Mellor Stephen

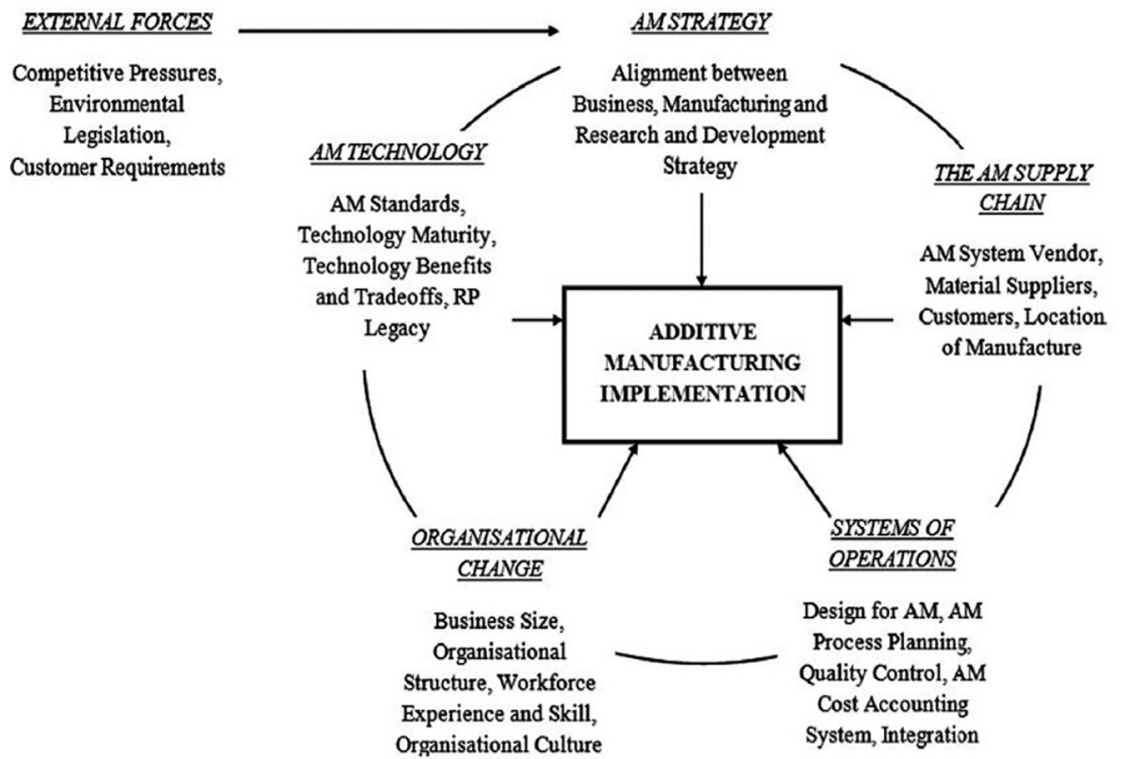

Sources: Mellor et al. (2013); Mellor (2014)

Figure 2 Framework for AM implementation for mass customization

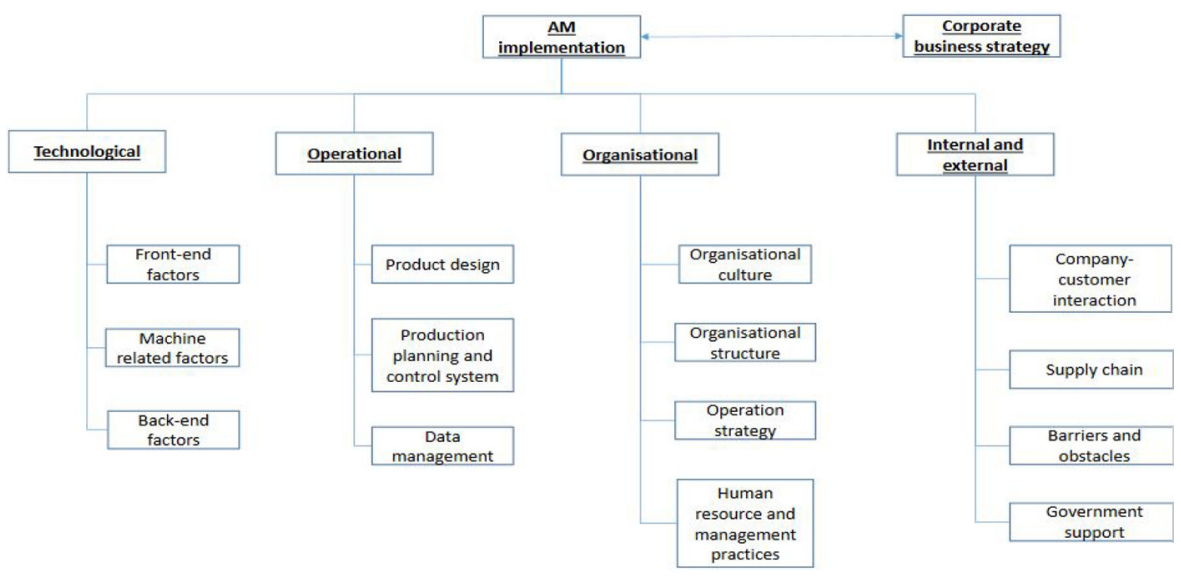

Source: Deradjat and Minshall (2015)

commissioning and post-commissioning phases). Each of the factor in the framework has sub-functions that supports the main factor; for instance, external factors have customer requirement, competitive pressure, collaboration, and regulation as sub-variables. The findings from this study shows how RM implementation for MC requires diverse considerations based on the phase of implementation and the maturity level of the technologies involved (Deradjat and Minshall, 2017).

Handal (2017) noticed that there is little literature in the research domain of AM that shows its impact on supply chain management and there is no complete toolset identified in manufacturing sector that can be used to assess the impact of $\mathrm{AM}$ and to ascertain suitable production techniques for supply chain management strategy. Therefore, a conceptual framework was developed to describe when AM impacts supply chain management, which was based on theories reviewed from literatures (Walter et al., 2004; Tuck and Hague, 2006; Ruffo et al., 2006). The factors used in the conceptual framework consist of three main factors i.e. (Manufacturing strategy, Supply chain strategy and Manufacturing system) as presented in Figure 4. The theoretical framework developed was based on (Fisher, 1997) framework which suggests two supply chain strategies fundamental, i.e. first, efficiency in production strategy which is characterized by (end-end optimization, shorttime to market, and continuous production) and secondly, responsiveness to market strategy which is also being characterized by (agility, flexibility, and customization). 
Figure 3 Framework for rapid manufacturing implementation for mass customization in dental industry

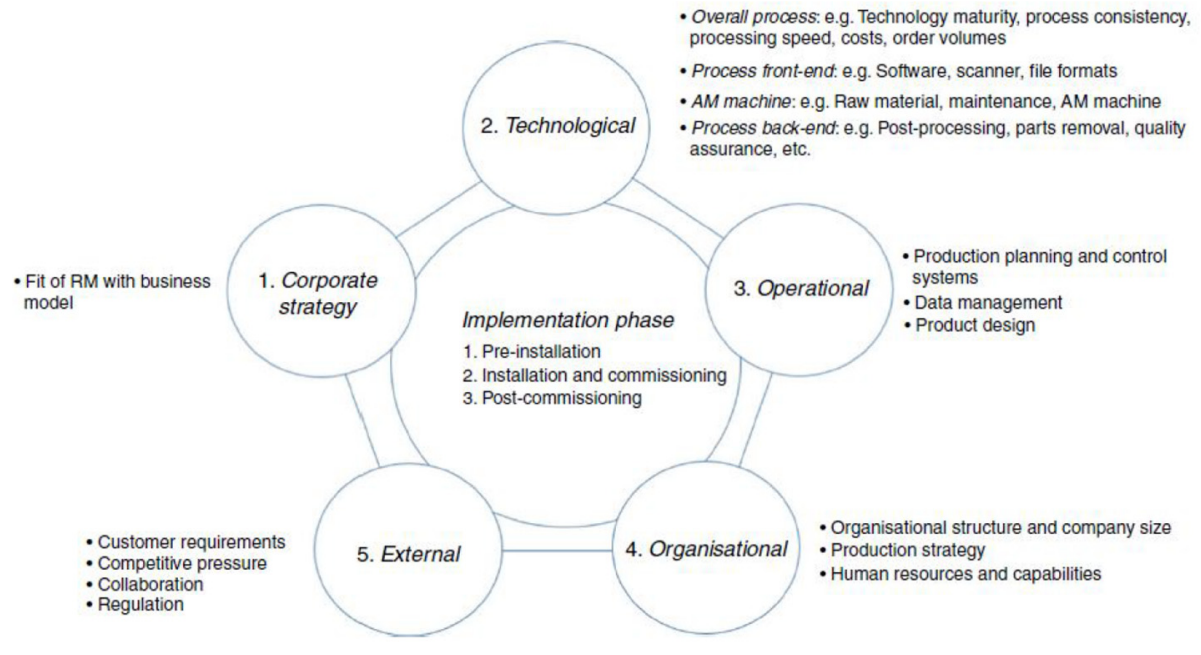

Source: Deradjat and Minshall (2017)

Figure 4 Conceptual framework for AM implementation in SCM

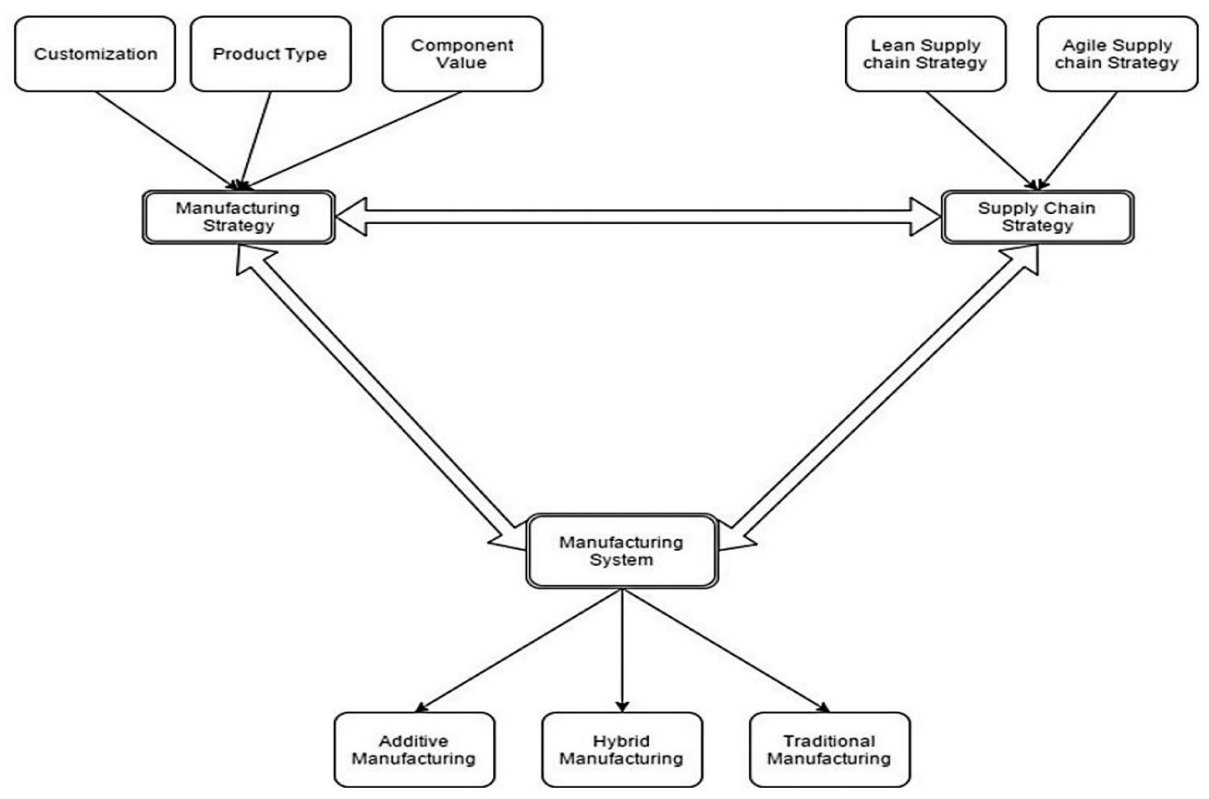

Source: Handal (2017)

In another study, Yeong and Chua (2013) develop a quality management framework for implementing AM for medical devices. The proposed framework considers some factors such as input data, process understanding, material management, product understanding, equipment qualification for AM. The framework also shows the interrelations between the factors from input materials to final production of AM parts. The authors believe that the framework would accelerate and ease the adoption rate of AM technologies as actual manufacturing method. Furthermore, Pradel et al. (2018) research entitled "a framework for mapping design for additive manufacturing knowledge for industrial and product design" collates and organizes the research field of design for AM (DfAM) knowledge through single and well-organized conceptual framework. The framework consists of five parts/factors, namely:

1 conceptual design;

2 embodiment design;

3 detail design;

4 process planning; and

5 process selection which were based on generic design process.

2.2 Recent studies on additive manufacturing education Over the years, many studies have been conducted within the engineering education context, but few studies were directly 
focus on AM education. However, of recent, few studies were specifically tailored towards $A M$ education and therefore, in this section, some recent studies on AM education from an engineering perspective were reviewed and presented.

Colletti (2016) study aimed to determine the positions available and the education and skills required to be successfully working in the field of AM. This study also identifies the types of companies that required AM expertise within their workforce and the location of these types of companies. The research methodology applied in this study was "mixed-methods" which involves two content analyses. The first part of this study analyzed 286 positions with appropriate search descriptions collected from five search engines which are basically designed for job purposes. The second part of this study was based on the analysis of the information available on AM education and training programs. The third approach in the study involved the use of a questionnaire which was circulated amount 2,000 members of AM Users Group and 1,000 attendees of a yearly conference on AM which was organized by the Society of Manufacturing Engineers and the data collected were analyzed using descriptive statistical tools. The results of the study show that $\mathrm{AM}$ is playing an important role from - Business strategy perspective, Companies' culture and Organization structures of organizations.

Furthermore, Colletti (2016) study shows that the highest degree needed for the position of manufacturing engineer within AM industry is bachelor's degree while with non-specific engineering degree will require one to five year's work experience. The study shows that in the AM industry, the manufacturing and tooling industry are in high demand for trained and experience AM experts (Colletti, 2016). Colletti (2016) suggests that colleges and universities should assist in developing training programs and short course certificates that teaches new advancements in AM technologies in collaboration with industry and professionals in various organizations. This study can be used as baseline for colleges and universities in the development of AM curriculum, certification courses, and training for students, academics and professionals in industry. The outcomes of this study can be used by companies in collaboration with academia in talent and workforce development in the field of AM. However, the findings in this study shows that AM education and skills is still lacking within the manufacturing workforce (Colletti, 2016).

Serdar (2016) study addresses the educational challenges involved in design for AM. This study suggests that students need to learn how to design for both complex and customized parts for future uses of AM. AM long-term success depends on the ability of the designers or STEM workforce that can think conceptually different compare to the conventional ways. The "MET1172 - CADD/CAE course" assignment was modified to assist students' visualization and improve student design skills with complex geometries using AM technologies for products development and manufacturing (Serdar, 2016). More requirements were added to MET1172 course project that allows the students to design from AM technology point of view and such approach is called "Inquire-based learning activities" i.e. the ability of the students to "learn by doing". The study also addresses various challenges that students encountered during designing for $\mathrm{AM}$ and such challenges include:

- the ability of the students to visualize complex geometries; and

- designing using complex Computer Aided Design (CAD) features.

Finally, the class evaluates the MET1172 projects and it was indicated that the project aspect made a valuable contribution to students' learning experience.

Similarly, a study was conducted by Minetola et al. (2015) to investigate the "impact of additive manufacturing on engineering education - evidence from Italy". The study evaluates the way direct access to AM machines could impact future mechanical engineering education using a Master of Science program in Mechanical Engineering at the "The Polytechnic University of Turin in Italy" as the case study; the study uses "questionnaire" to carry out a survey and the questionnaire consists of both closed and open and ended questions. The questionnaire was designed specifically to evaluate the relevance of an entry-level AM machines i.e. desktop $3 \mathrm{D}$ printers within the learning environment and as a tool for project development (Minetola et al., 2015). The survey was administered to three consecutive groups of students anonymously who attend "Computer-Aided Production" (CAP) course within the postgraduate degree programmes in Mechanical Engineering. The CAP course consists of a practical project that allows the students to design, fabricate and assemble prototype and final part. The findings from the study showsthat "there is a positive relationship of access to AM systems to perceive interest, motivation and ease of learning of mechanical engineering". The results of the study show that entry-level FDM AM technology provides the students and lecturers with hands-on-experience. More so, the outcomes of this study indicate that it promotes technical knowledge acquisition and early exposure of students to AM tools that would make them have a "think additive" mind set to product design and development (Minetola et al., 2015).

In another multi-disciplinary research conducted by Gatto et al. (2015) with focus on engineering education, that is, an approach into learning with AM and reverse engineering. This study was conducted at an Italian university called University of Modena and Reggio Emilia. The study used "cooperativelearning project" of second-year course within a Master of Science degree program in Mechanical Engineering as the case study. The aim of the study was to "create awareness of the educational impact of AM and reverse engineering". To achieve the aim of the study, the students were asked to develop a design and manufacturing solution for an eye-tracker head mount concurrently using AM techniques and the eye-tracker head model was reverse engineered. The practical project required the students to test the prototype, perform cost analysis and evaluate. The findings from the study shows that the study supports the "authors' belief in the tremendous potential of interdisciplinary project-based learning, relying on innovative technologies to encourage collaboration, motivation and dynamism".

Despeisse and Minshall's (2017) recent publication entitled "skills and education for AM: a review of emerging issues"; the study addresses the present talent shortage needed to deliver 
necessary skills and knowledge for an effective deployment of AM technologies. The study was based on literature reviews and evidence collected through different stakeholder workshops. The study identifies various issues and barriers perceived hindering the adoption and exploitation of AM. The study summarizes some basic skills for AM and recommendations were made for $\mathrm{AM}$ education program to enhance the AM skills for students, lectures, designers, engineers and managers in various industries. The common AM barriers identifies include - lack of specific design skills, uncertainties in part qualification, lack of standard in production and limited materials to work with. In this study, Despeisse and Minshall (2017) states that there was a strong need to effectively educate future engineers on AM technologies as many engineering students both at the university and industry are not familiar with AM technologies and this was recognized as a crucial barrier for industrial adoption of AM technologies. Despeisse and Minshall (2017) concludes their study with a mind-map representation with the main issues poorly placed at the centre in bold letters and recommendations for $\mathrm{AM}$ education and training arranged around the issues/barriers as shown Figure 5.

Among other studies on AM education at some universities is Radharamanan's (2017) study on AM in manufacturing education, implementation and development of a new course at the Mercer University, School of Engineering. Drakoulaki (2017) study at the University of Oslo, Norway focused on " $3 \mathrm{D}$ printing as learning activity in the higher education" and the study centers on the learning aspect of AM education among higher education students. Drakoulaki (2017) also study addresses the problem of "how $3 \mathrm{D}$ printing may support learning and knowledge construction in the university and how this activity relates to students". In another study by Harvey (2016) entitled "Teaching Additive Manufacturing in a Higher Education Setting" - a University of Wollongong, School of Mechanical, Materials, and Mechatronics Engineering case study. The study evaluates the effectiveness of teaching AM to final year engineering students at the university using projectbased learning approach. The university established an "AM laboratory" which is equipped with seven $3 \mathrm{D}$ printers for the use of students. The students were able to build new learning skills in Computer-Aided Design (CAD) and related "soft skills", for instance, project management and quality assurance (Harvey, 2016).

\section{Research methodology}

This study uses qualitative research methodology and the primary data was collected using structured questionnaire which was distributed among the university students and academics. The questionnaire was carefully designed based on comprehensive literature reviews conducted and five factors were identified useful for the construction of the entire questionnaire. The research methodology for this study went different stages i.e. formulation of research title, identifying of research problem, data collection, data analysis and interpretation of results, hypotheses formulation and testing and development of new scientific theory/framework. However, there are three significant stages in the research methodology. First, a pilot survey was conducted, and the questionnaires were sent via email to 25 people comprising of the academia, postgraduate students, post-doctoral research

Figure 5 The mind-map of recommendations for AME and training and its associated issues

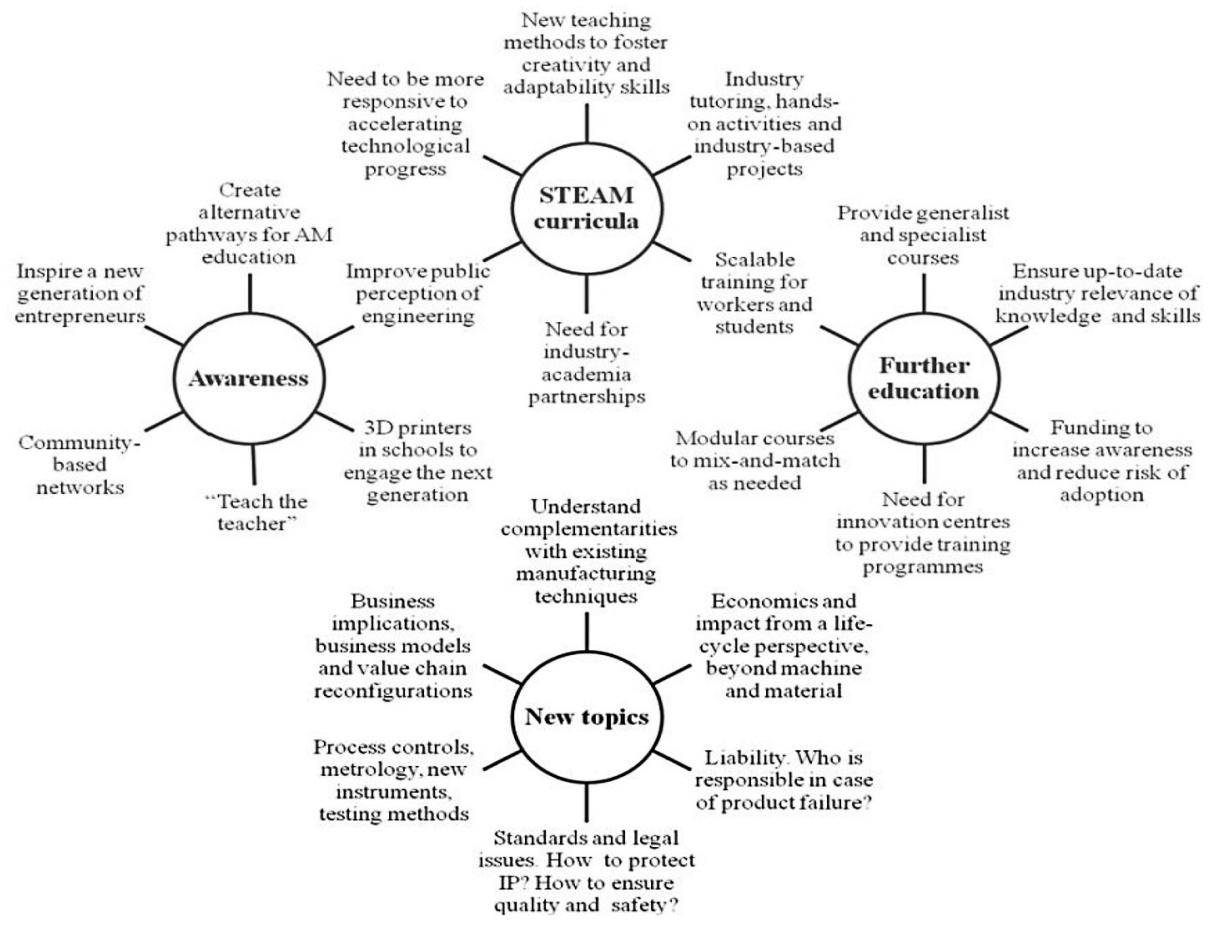

Source: Despeisse and Minshall (2017) 
fellow and industry experts in $\mathrm{AM} / 3 \mathrm{D}$ printing technology to assist in completing the questionnaires and to provide relevant feedback on how to improve the questionnaire if necessary. The validity of the measuring instrument was improved based on the feedback of 11 people that completed the questionnaire for the pilot survey. Secondly, the questionnaires were distributed for the main data was collected among students and academics; and appropriate hypotheses were stated. The third important stage of the study involves the statistical analysis of the data using SPSS statistical tools, the results were discussed and interpreted, the hypotheses were tested and the framework for AME was developed.

\section{Population and sample size for the study}

Burmeister and Aitken (2012) describe sample size as:

One element of research design that investigators need to consider as they plan their study. Although sample size is a consideration in qualitative research, the principles that guide the determination of sufficient sample size are different to those that are considered in quantitative research

Burmeister and Aitken (2012) recommend that researchers can use sample size calculator to determine effective sample size and suggested that a sample of 100 should be sufficient for a quantitative research method. In most cases, sample sizes between 30 and 500 are generally accepted as sufficient for a quantitative study by many researchers (Delice, 2010). Therefore, this study uses sample size of 130 participants, and which implies that the sample size used for this study is considered suitable for this type of research, would answer the research questions and allows generalization of the findings. In summary, a total number of 200 questionnaires were handed out to the target audience for this study and 130 completed questionnaires were returned (a 65 per cent response rate) while 70 questionnaires were not return (a 35 per cent nonresponse rate). Out of the 26 universities in South Africa, four universities were considered for this survey and this was based on their strong involvement in AM research and the presence of the state-of-the-art AM facilities at these universities. The selected universities are - Vaal University of Technology (VUT), North-West University (NWU), University of Johannesburg (UJ) and University of the Witwatersrand (WITS).

\section{Measuring instrument for this study}

A structured questionnaire was used as the measuring instrument for this study. The questions were designed based on a comprehensive literature study as relating to AME. The factors were identified from literature reviews and used to develop the measuring instrument. The five factors/variables were considered suitable to foster effective AME at the universities both in South Africa and globally. The entire questionnaire is divided into dependent and independent variables. The questionnaire consists of a well-detailed cover letter that explains the purpose of the study to the participants. The measuring instrument comprises of two sections (i.e. section A and section B). Section A contains the biographical information section and section $\mathrm{B}$ contains the main body of the questionnaire.

The first sub-section in the main body of the questionnaire comprises of questions that measures the respondents understanding and perception about "additive manufacturing technology" and the impact of the technology to science and engineering education based on their years of working with either high-end additive manufacturing or entry-level desktop3D printing systems. The second sub-section, third sub-section, four sub-section and fifth sub-section contained questions under $\mathrm{AM}$ technology transfer, $\mathrm{AM}$ educational curriculum, AM in-house facilities and AM research and development respectively. Furthermore, the questionnaire contains two open-ended questions. The five factors/variables considered in the questionnaire are described briefly below:

1 AM Technology: This is the first sub-section in section $\mathrm{B}$ and each question was designed with an intent to examine the degree at which each respondent understands AM technology; and their perception/observation as relating to AM technology from an education point of view.

2 AM Technology Transfer: The questions in this second subsection aimed at examining the respondents' level of understanding and perception in relation to technology transfer by exploring the importance of universityindustry collaboration and the benefits that $3 \mathrm{D}$ printing bureau could offer.

3 AM Educational Curriculum: The questions in this subsection were asked to examine the respondents' perspective as regarding the importance of AM education and its inclusion in the science and engineering curriculum at the university.

4 AM In-House Facilities: The questions in this sub-section were asked to examine if the current AM facilities at the respondents' universities are available for the use of students and for promoting AM education.

5 AM Research and Development (RED): Research and development is expected to play a significant role in the advancement of AM education at the universities. The questions in this sub-section aimed to measure respondents' perspective as relating to $\mathrm{R} \& \mathrm{D}$ and its importance in AM education framework.

\section{Results, analysis and discussions}

This section presents a comprehensive discussion of the statistical analysis and results/findings. This section comprises of two sections:

1 the biographical information of the respondents; and

2 the main body of the questionnaire where the respondents indicate their level of agreement to each question within the constructs.

\subsection{Interpretation and discussion of section a of the} questionnaire - biographical information

The gender of the respondents shows 73 males $(n=56.2$ per cent) and 57 females $(n=43.8)$ out of 130 participants. The percentage of male and female in the survey, shows that males and female are embracing AM technology within the education sector as shown in Figure 6(a). The age group of the majority of the respondents were within the age groups of 21-25years ( $n=70 ; 53.8$ per cent) and follows by $26-30$ years $(n=40 ; 30.8$ per cent), and age groups within 31-35years have 10 respondents ( 7.7 per cent), while age groups $15-20,36-40$ and 
Figure 6 Shows the gender and age range of the respondents

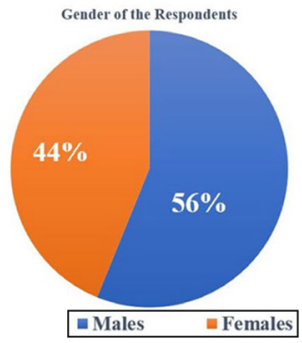

(a)

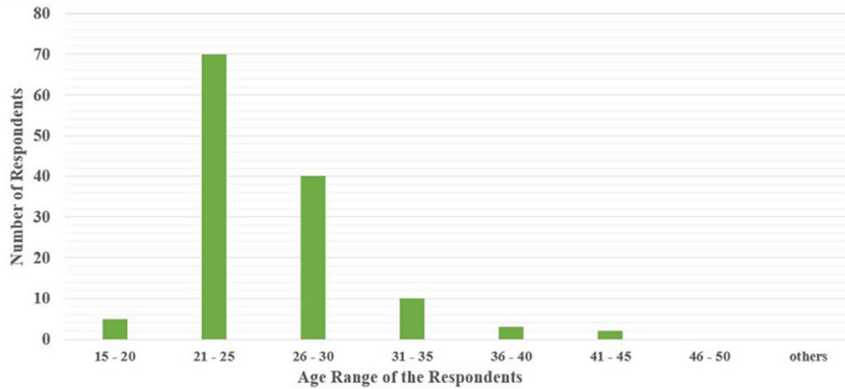

(b)

Notes: (a) Gender of the respondents; (b) age range of the respondents

41-45 have 5, 3 and 2 respondents respectively as shown in Figure 6(b).

To identify the number of postgraduate students that participated in the survey and their involvement in AM technology, the respondents were asked to indicate their level of study (i.e. honors, masters and doctoral degree), 61 respondents were postgraduate students i.e. [master degree level $(n=36 ; 27.7$ per cent), doctoral degree level ( $n=14 ; 10.8$ per cent) and honors degree level ( $n=11 ; 8.5$ per cent)] as shown in Figure $7(\mathrm{a})$. The respondents were asked to indicate their universities name, and the selected universities were earlier mentioned in section 4 of this paper. VUT has the highest number of respondents that participated in the survey which covers their two campuses (Main and Sebokeng campuses). As shown in Figure 7(b), Vaal
University of Technology has ( $n=64 ; 49.2$ per cent), North-West University ( $n=28 ; 21.5$ per cent), University of Johannesburg ( $n=18 ; 13.8$ per cent) and University of the Witwatersrand $(n=20 ; 15.4$ per cent). The respondents within the undergraduate degree were asked to indicate their year of study and the main reason for this question is to identify undergraduate students' year of study and their level of involvement using AM technology. Out of 130 participants, 59 of respondents are undergraduate students; and 38 respondents indicate year 4, 14 respondents indicate year 3, 4 respondents indicate year 2 and 3 respondents indicate year 1 as shown in Figure 7(c).

Some of the participants in the survey are working within the university environment and the respondents in this category were requested to indicate their "position within the university" as

Figure 7 Shows the level of degree of postgraduate's respondent, name of respondents' universities/organizations, years of study undergraduate degree and position of the respondents within the universities/organization

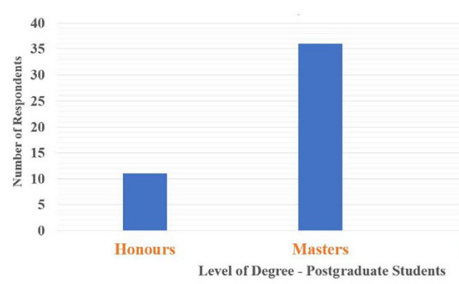

(a)

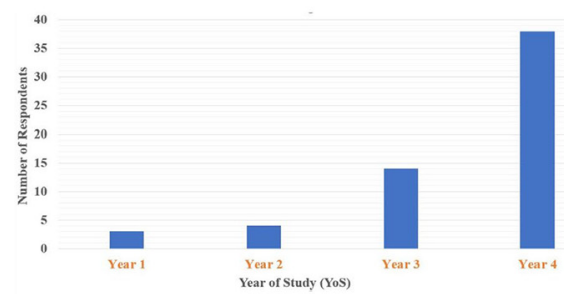

(c)

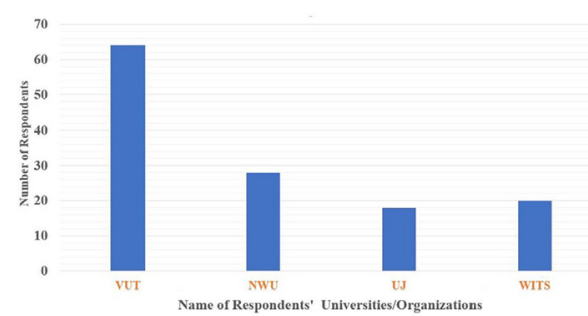

(b)

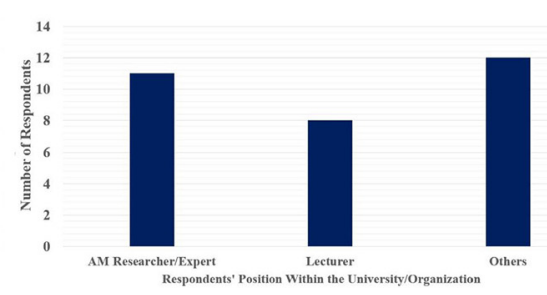

(d)

Notes: (a) The respondents' level of degree - postgraduate students; (b) name of respondents' universities/organaizations; (c) respondents' year of study - undergraduate students;

(d) respondents' position within the university/ogranization 
[academic staffs or AM experts/researcher]. Out of 31 respondents within this category, 11 respondents indicate "AM researchers/experts" position while 8 respondents indicate "lecturer" either [junior and senior lecturers] and 12 respondents indicate "other" which implies [lab Technician, lab assistant, head of department working within the AM environment, postdoctoral fellows] as presented in Figure 7(d). The respondents were asked to indicate their fields of study to show which fields of study have greatly embraced AM education and research. As shown in Figure 8(a), Mechanical Engineering has the highest percentage with $(n=44 ; 33.8$ per cent), Electrical Engineering ( $n=18 ; 13.8$ per cent), Industrial Engineering $(n=17 ; 13.1$ per cent), Chemical Engineering ( $n=8 ; 13.8$ per cent) and soon as presented in Figure 8(a). In this survey, science related degree is referred to other science and engineering related degrees that the authors could not list i.e. [Geology, Biomedical Engineering, Computer Science, Metallurgical Engineering, Biochemistry, Chemistry, Physics, Architectural Design] as indicated by the respondents. More so, others in this regard referrs to fields of study in "Human resource management, Operational Management, Legal science, Fine Arts, Business Management, Business Administration" as indicated by the respondents as shown in Figure 8(a).

Finally, the respondents were asked to indicate their level of experience with AM technology and the essence of this question is to know if the majority of the respondents have certain knowledge or experience working with AM technology as (Basic, Intermediate, AM expert and Novice experience of AM technology). This question was also used to test the respondents' capability in completing the section B of the questionnaire effectively. Out of 130 participants, 59 respondents indicate 'Basic", 50 respondents indicate "Intermediate", 17 respondents indicate "AM expert" and only 4 respondents indicate "Novice" as shown in Figure 8(b). Majority of the respondents indicates either "basic and intermediate" which implies most of the participants have accessed to AM facilities and have worked either the entry-level Desktop 3 D printing machines or Industrial AM Machines.

\subsection{Framework responses - statistical analysis of section $B$ of the questionnaire}

This section discussed the section $\mathrm{B}$ of the questionnaire (the main body of the questionnaire) which comprises of five variables/factors. These factors formed the basis for stated hypotheses [i.e. null $(\mathrm{HO})$ and alternative $(\mathrm{H} 1)$ ] and this led to the development of the questionnaire which serve as a means for testing the hypotheses. The next sub-sections present the discussions and general descriptive statistical analysis of each of the five variables/factors used in the questionnaire as presented in tables form. The tables show the frequency percentage, the mean (M) and the standard deviation (SD) of the respondents' feedback and the internal reliability (i.e. Cronbach alpha) and average inter-item correlation. Statistically, the questions in each construct were further divided for easy grouping using pattern matrix as part of the factor analysis.

\subsubsection{Descriptive statistical analysis - additive manufacturing technology}

The questions in this sub-section were directly related to the "fundamental of AM technology and its relation to education" and the questions aimed to examine the impact of AM on science and engineering education. Table I shows the general descriptive statistical analysis with the percentage responses from 130 respondents. The questions within this sub-section were divided into four constructs and each contained both internal reliability and average inter-item correlation. Therefore, the internal reliability (i.e. Cronbach's alpha) for the four constructs are $0.853,0.762,0.657$ and 0.872 respectively and the average inter-item correlations are $0.463,0.351,0.328$ and 0.696. The Cronbach's alpha for this sub-section are considered an acceptable reliability coefficient which implies that the items contained a relatively high internal consistency (Nunnally and Bernstein, 1994; Reynaldo and Santos, 1999). The Kaiser-Meier-Olkin (KMO) for this sub-section is 0.788 which measure the sample adequacy and exceed the "acceptable good value" of 0.70. To test if the correlations between items are higher enough, the Bartlett's test of sphericity is approx. chi-square 1102.310 and reached statistical significance of $(p<0.000)$, although if $p<0.05$, the correlations are considered sufficiently high (Pallant, 2011).

As shown in Table I, the questions in construct 1 centered on the "application or usefulness of AM technology" in various sectors such as manufacturing, engineering, dental and medical, etc. and majority of the responses agreed that AM is very useful in various sectors. The questions in the second construct focused on the "importance and advantages of AM

Figure 8 Shows the respondents' field of study and level of experience working with am technology

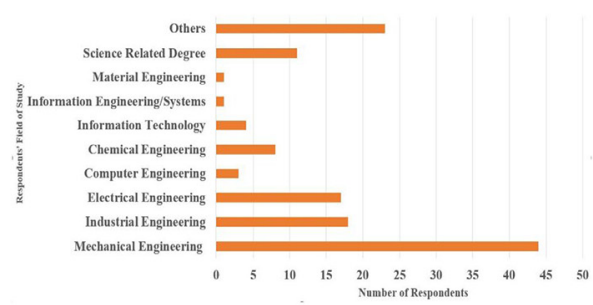

(a)

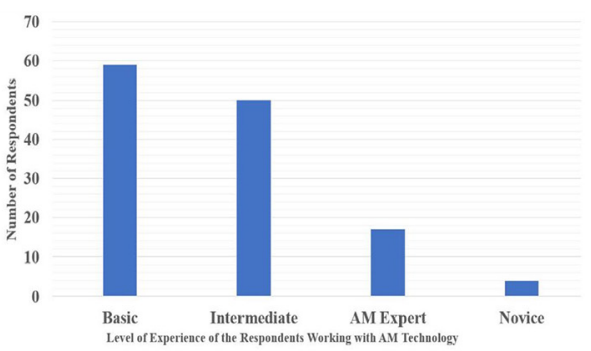

(b)

Notes: (a) Respondents' field of study; (b) level of experience of the respondents working with AM technology 
Table I AM Education and technology related questions and respondents' responses (per construct)

AM Technology - Sub-section 1

Liker Scale used - 1: Strongly Disagree; 2: Disagree; 3: Neutral; 4: Agree; 5: Strongly Agree

$\begin{array}{ll}\text { Construct 1: } & \text { Applications/ Usefulness of AM technology } \\ 1.1 \mathrm{AM} \text { has been found to be useful in the following sectors } \\ 1.1 \mathrm{a} & \text { Manufacturing } \\ 1.1 \mathrm{~b} & \text { Industrial Design } \\ 1.1 \mathrm{C} & \text { Engineering } \\ 1.1 \mathrm{~d} & \text { Dental and Medical } \\ 1.1 \mathrm{e} & \text { Automotive } \\ 1.1 \mathrm{f} & \text { Aerospace } \\ 1.1 \mathrm{~g} & \text { Education }\end{array}$

$1(\%) \quad 2(\%)$

$3(\%)$

$4(\%)$

$5(\%)$

$\mathrm{M}(\%)$

SD (\%)

Construct 1: Applications/ Usefulness of AM technology

$\begin{array}{ll}0 & 0 \\ 0 & 1.5 \\ 0 & 0 \\ 1.5 & 1.5 \\ 0 & 2.3 \\ 0 & 3.8 \\ 0 & 3.8\end{array}$

$\begin{array}{rr}4.6 & 50.8 \\ 6.2 & 51.5 \\ 5.4 & 47.7 \\ 13.8 & 39.2 \\ 12.3 & 43.8 \\ 8.5 & 43.1 \\ 4.6 & 50.0\end{array}$

$\begin{array}{lll}44.6 & 4.40 & 0.579 \\ 40.8 & 4.32 & 0.659 \\ 46.9 & 4.42 & 0.594 \\ 43.8 & 4.22 & 0.856 \\ 41.5 & 4.25 & 0.758 \\ 44.6 & 4.28 & 0.780 \\ 41.5 & 4.29 & 0.731\end{array}$

Construct 2: importance and advantages of AM technology 1.2 AM technology has been found to

$\begin{array}{ll}1.2 \mathrm{a} & \text { Reduces waste material } \\ 1.2 \mathrm{~b} & \text { Brings down labor cost } \\ 1.2 \mathrm{c} & \text { Speeds up the development } \\ 1.2 \mathrm{~d} & \text { Speeds up the test phase } \\ 1.2 \mathrm{e} & \text { Allows for product customization } \\ 1.2 \mathrm{f} & \text { Ability to make complex metal parts }\end{array}$

Construct 3: The present and future impacts of AM technology on science and engineering education

\begin{tabular}{|c|c|c|c|c|c|c|c|c|}
\hline 1.3 & AM creates opportunity to improve new product development & 0 & 0 & 6.9 & 48.5 & 44.6 & 4.38 & 0.613 \\
\hline 1.4 & $\begin{array}{l}\text { AM education enhances the Science \& Engineering degree at } \\
\text { the university in South Africa }\end{array}$ & 0 & 6.2 & 10.0 & 50.0 & 33.8 & 4.12 & 0.822 \\
\hline & $\begin{array}{l}\text { From Advance Manufacturing perspective, AM is regarded as } \\
\text { a sustainable technology }\end{array}$ & 0.8 & 0 & 30.0 & 43.1 & 26.2 & 3.94 & .795 \\
\hline & All the $3 \mathrm{D}$ printing Labs at South Africa universities, & 0 & 0 & 14.6 & 43.1 & 42.3 & 4.28 & 0.705 \\
\hline
\end{tabular}
specifically the "Idea 2 Product" Lab at VUT and NWU Pukke 3 D Printing Centre equipping students and professionals with both basic and in-depth knowledge of the AM technology

\section{Construct 4: Accessibility and acquisition of fundamental knowledge AM technology}

\begin{tabular}{|c|c|c|c|c|c|c|c|c|}
\hline 1.5 & $\begin{array}{l}\text { Most science \& engineering students at SA universities have } \\
\text { fundamental knowledge of AM }\end{array}$ & 2.3 & 16.9 & 21.5 & 34.6 & 24.6 & 3.62 & 1.102 \\
\hline 1.6 & $\begin{array}{l}\text { A number of science \& engineering students at South African } \\
\text { universities have access to AM technology for design } \\
\text { purposes }\end{array}$ & 3.8 & 13.8 & 12.3 & 46.2 & 23.8 & 3.72 & 1.093 \\
\hline 1.7 & $\begin{array}{l}\text { A number of science \& engineering students at my university } \\
\text { has access to AM technology for prototyping purposes }\end{array}$ & 0.8 & 16.9 & 22.3 & 40.0 & 20.0 & 3.62 & 1.015 \\
\hline
\end{tabular}

technology" and most responses from the respondents recorded significant level of agreement. The third construct contained questions that focused on the "present and future impacts of AM technology on science and engineering education" and majority of the respondents level of agreement to these questions show that $\mathrm{AM}$ is creating more opportunities to improve new product development and also indicates that the current $3 \mathrm{D}$ printing labs at selected South African universities are being used to equipp both students and professionals with needed basic and advanced knowledge of $\mathrm{AM}$. The last construct contained questions that centered on the "accessibility and acquisition of fundamental knowledge of AM technology". This questions in the construct recorded high percentage of neutral, strongly disagree and disagree responses from the respondents, and this implies that there is still very low accessibility to AM and the acquisition of basic knowledge of
AM technology among science and engineering students at the universities in SA. Correlation are expected to be statistically significant at the level of 5 per cent i.e. $p>0.005$ (Miller et al., 2012; Pallant, 2011: 100; Piedmont, 2014). The inter-items correlation matrix was conducted based on each construct, and this indicated that construct $1,2,3$ and 4 are statistically significant at level $0.50,0.40,0.30$ and 0.60 respectively. Based on the key guidelines to identify component correlation matrix $(\sim 0.1$, small, no practical significant relationship, $\sim 0.3$, medium, practical visible relationship, and $\sim 0.5$, large, practical significant relationship). Therefore, the correlation coefficient between first and second constructs is 0.124 which implies no practical significant relationship between the construct, while the correlation coefficient between third and fourth constructs is 0.206 which implies a small relationship exist. 


\subsubsection{Descriptive statistical analysis - additive manufacturing technology transfer}

The questions within this sub-section of the questionnaire directly related to "technology transfer from an AM technology perspective" as shown in Table II. The aim of this sub-section is to examine the importance of technology transfer in promoting AM technology within the education sector. The first, second and third construct exhibited an internal reliability of $0.883,0.840$ and 0.615 Cronbach alpha respectively. The three Cronbach's alpha are considered acceptable reliability coefficients (Nunnally and Bernstein, 1994). The KaiserMeier-Olkin (KMO) for this sub-section is 0.746 which measures the sample adequacy and exceeds the "acceptable good value" of 0.70 . To test if the correlations between items are high enough, the Bartlett's test of sphericity is approx. chisquare 915.226 and reached statistical significance of $(p<0.000)$. The questions in the first construct centered on the "aim, roles and importance of technology transfer" within the context of AM. Most of the responses from the respondents indicate that that technology transfer provides skills development for the students and university staffs. This also shows that technology transfer is playing a significant role in the development and integration of AM education at the university.

The questions in second construct focused on the "benefits of the university-industry collaboration in AM technology transfer" and the feedback from the respondents show that the respondents understand the importance of university-industry collaboration in the advancement of AM education and in enhancing cutting edge research at the universities. The questions in the third construct focused on the "involvement of
$3 \mathrm{D}$ printing service bureau in AM technology transfer" and the respondents' feedback shows that the involvement of $3 \mathrm{D}$ printing service bureau would provide both hands-on and onthe-job experience of AM technology to the students, academics and industry professionals if there is a strong relationship between the university and $3 \mathrm{D}$ printing service bureau in the country. Due to the present of negative values, the inter-items correlation matrix for this sub-section is statistically significant at the level of $0.50,0.60$ and 0.40 for the three constructs (Piedmont, 2014). Based on the key guidelines to identify component correlation matrix, the relationship between the "first and second" constructs have correlation coefficient of 0.357 which implies medium relationship. Likewise, the relationship between "second and third" constructs is medium relationship with correlation coefficient of 0.384 . This indicates that there is "practical visible relationship" in the three constructs.

\subsubsection{Descriptive statistical analysis - additive manufacturing educational curriculum}

The set of questions within this sub-section of the questionnaire centered on the "importance of educational curriculum in AM technology". This sub-section aimed to examine the need for inclusion of AM education in the university curriculum and which will eventually promote effective career path and increase professionals in the field of AM technology. Pattern matrix was conducted to obtain suitable grouping and the questions were divided into three constructs as presented in Table III. The first, second and third constructs exhibited an internal reliability of $0.827,0.870$ and 0.695 of Cronbach alpha respectively (i.e. an acceptable reliability coefficients). The Kaiser-Meier-Olkin (KMO) for

Table II AM Technology transfer related questions and respondents' responses (per construct)

AM Technology Transfer - Sub-section 2

Liker Scale: 1: Strongly Disagree 2: Disagree 3: Neutral 4: Agree 5: Strongly Agree

$1(\%) \quad 2(\%) \quad 3(\%) \quad 4(\%) \quad 5(\%) \quad M(\%) \quad S D(\%)$

Construct 1: Aim, roles and importance of Technology Transfer

2.1 Technology transfer is the process of passing theoretical and practical skills,

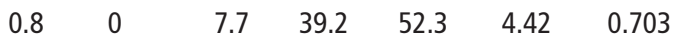

knowledge, manufacturing processes \& technologies from the owner of a technology to a wider range of users

2.2 Technology transfer ensures:

2.2a Scientific and technological development become more available in industry

2.2b Skills development of the university academic staff

2.3 Technology transfer plays a major role:

2.3a In the development of AM education at the university

2.3b In the integration of AM education at the university

$\begin{array}{llrrrrr}0 & 0.8 & 9.2 & 45.4 & 44.6 & 4.34 & 0.677 \\ 0 & 0.8 & 11.5 & 45.4 & 42.3 & 4.29 & 0.698 \\ & & & & & & \\ 0 & 0.8 & 15.4 & 44.6 & 39.2 & 4.22 & 0.729 \\ 0.8 & 0 & 13.8 & 44.6 & 40.8 & 4.25 & 0.748\end{array}$

Construct 2: Benefits of University-Industry collaboration in AM Technology Transfer 2.4 University-industry collaboration on AM processes will

2.4a Further enhance the university academic relations with industry

2.4b Further enhance the university students' relations with industry

2.4c Promote more research at the university

2.4d Attract more scholarships/bursary to the universities

2.4e Attract more internships for the student at the university

$\begin{array}{llrllll}0 & 0.8 & 5.4 & 57.7 & 36.2 & 4.29 & 0.603 \\ 0 & 0 & 5.4 & 60.8 & 33.8 & 4.28 & 0.560 \\ 0 & 0.8 & 8.5 & 54.6 & 36.2 & 4.26 & 0.642 \\ 0 & 4.6 & 17.7 & 43.8 & 33.8 & 4.07 & 0.837 \\ 0 & 6.2 & 18.5 & 41.5 & 33.8 & 4.03 & 0.880\end{array}$

Construct 3: Involvement of 3 D printing service bureau/company in AM Technology Transfer

2.5 3D printing service bureau or organization would provide students, academics and industry engineers:

\begin{tabular}{|c|c|c|c|c|c|c|c|c|}
\hline $2.5 a$ & With hands-on experience & 0 & 0 & 9.2 & 53.1 & 37.7 & 4.28 & 0.625 \\
\hline $2.5 b$ & With on-the-job experience. & 0.8 & 8.5 & 13.8 & 43.1 & 33.8 & 4.01 & 0.944 \\
\hline
\end{tabular}


Table III AM Educational curriculum related questions and respondents' responses (per construct)

\begin{tabular}{|c|c|c|c|c|c|c|c|c|}
\hline \multicolumn{9}{|c|}{$\begin{array}{c}\text { AM Educational Curriculum - Sub-section } 3 \\
\text { Liker Scale: 1: Strongly Disagree 2: Disagree 3: Neutral 4: Agree 5: Strongly Agree }\end{array}$} \\
\hline & & $1(\%)$ & $2(\%)$ & $3(\%)$ & $4(\%)$ & $5(\%)$ & $M(\%)$ & SD (\%) \\
\hline \multicolumn{9}{|c|}{ Construct 1: Need for more $A M$ personnel in the field of $A M$} \\
\hline 3.1 & $\begin{array}{l}\text { More educated personnel in the field of AM are needed in South Africa } \\
\text { as the technology is rapidly growing at an exponential speed across } \\
\text { industries }\end{array}$ & 0 & 0 & 3.8 & 43.1 & 53.1 & 4.49 & 0.574 \\
\hline 3.2 & AM education could be included in the relevant: & & & & & & & \\
\hline $3.2 \mathrm{a}$ & Undergraduate - science and engineering courses at the universities & 0 & 0 & 7.7 & 48.5 & 43.8 & 4.36 & 0.623 \\
\hline $3.2 b$ & Postgraduate - science and engineering courses at the universities & 0 & 0.8 & 5.4 & 54.6 & 39.2 & 4.32 & 0.613 \\
\hline 3.3 & $\begin{array}{l}\text { An introduction of AM technology courses as full-semester courses at } \\
\text { the university would enhance and promote the educational aspect of } \\
\text { the technology }\end{array}$ & 0 & 0 & 8.5 & 55.4 & 36.2 & 4.28 & 0.610 \\
\hline 3.4 & $\begin{array}{l}\text { An introduction of AM technology courses as full-semester course } \\
\text { would serve as mean to allow science and engineering students to } \\
\text { develop interest in AM and creates career path in AM technology }\end{array}$ & 0 & 0 & 7.7 & 53.1 & 39.2 & 4.32 & 0.610 \\
\hline \multicolumn{9}{|c|}{ Construct 2: Inclusion of AM education/courses in science and engineering curriculum } \\
\hline \multicolumn{9}{|c|}{ 3.5 A suitable short-course programmes should be designed for engineers in industry which could provide them with: } \\
\hline 3.5a & An exposure to AM machines ( $3 \mathrm{D}$ printers) & 0 & 0.8 & 3.1 & 51.5 & 44.6 & 4.40 & 0.592 \\
\hline $3.5 b$ & A hands-on-experiences of AM technology & 0 & 0 & 5.4 & 53.1 & 41.5 & 4.36 & 0.584 \\
\hline $3.5 \mathrm{c}$ & An exposure to design and simulation techniques & 0.8 & 0 & 10.0 & 49.2 & 40.0 & 4.28 & 0.705 \\
\hline \multicolumn{9}{|c|}{ Construct 3: Suitability of entry-level $3 D$ printers for $A M$ education } \\
\hline 3.6 & $\begin{array}{l}\text { Entry-level FDM desktop AM/3D printing machine is considered } \\
\text { suitable for AM education at the University Level }\end{array}$ & 0 & 0 & 7.7 & 53.1 & 39.2 & 4.32 & 0.610 \\
\hline 3.7 & $\begin{array}{l}\text { All the } 3 \text { D printing Labs at the South African universities, specifically } \\
\text { the "Idea } 2 \text { Product" Lab at VUT and "Pukke } 3 \text { D Printing Centre" at } \\
\text { NWU are equipping students and professionals with both basic and in- } \\
\text { depth knowledge of AM technology }\end{array}$ & 0 & 2.3 & 10.8 & 46.2 & 40.8 & 4.25 & 0.740 \\
\hline
\end{tabular}

this sub-section is 0.761 which measures the sample adequacy and exceeds the "acceptable good value" of 0.70 . To test if the correlations between items are high enough, the Bartlett's test of sphericity is approx. chi-square 595.237 which implies it reached statistical significance of $(p<0.000)$. The questions in the first construct focused on the "need for more AM personnel or experts in the field of $A M$ " to promote AM education and research at the universities. Majority of the responses from the respondents show that, the way to increase AM experts/ professionals in the field would come through the introduction of AM education curriculum/courses at the universities both at the undergraduate and postgraduate level, especially within the STEM education.

The second construct contained questions that centered on the "inclusion of $A M$ education/courses in the science and engineering curriculum or education" at the universities. The responses received from the respondents agreed that suitable short-course programmes should be designed for engineers and professionals in industry to expose them to AM technology. More so, the third construct contained questions that centered on the "suitability of entry-level $3 D$ printers for AM education" at the universities. Majority of the respondents' feedback indicates "agreed" which implies that entry-level 3 D printers are most suitable for AM education at the university level. The reason for high agree response can be linked to the fact that entry-level $3 \mathrm{D}$ printing machines are very affordable and easy to set up compared to high-end industrial AM machines which is very expensive and affordable for most universities to launch with a small lab at the universities. The correlation coefficients are expected to be statistically significant at the level of 5 per cent i.e. $p>0.005$. Therefore, the inter-items correlation matrix for this sub-section shows that the three constructs are statistically significant at the level $0.5,0.6$ and 0.7 respectively and the inter-items correlation contained no single negative value which indicates that all the items measured the same underlying characteristics (Pallant, 2011). The relationship between the first and second constructs is regarded as a "medium" with component correlation coefficient of 0.351 which implies there is practically visible relationship. The relationship between second and third constructs is considered "small" with component correlation coefficient of 0.098 which shows there is no practical significant relationship.

\subsubsection{Descriptive statistical analysis - additive manufacturing in-house facilities}

In this sub-section, the questions are directly focused on "the availability of $\mathrm{AM} / 3 \mathrm{D}$ printing machines to enhance and promote AM education and research at the universities". The questions in this sub-section aimed to examine the impact of inhouse AM facilities and state-of-the-art AM/3D printing lab at the university. Pattern matrix was conducted, and the questions were divided into three constructs as shown in Table IV. The three constructs exhibited an acceptable reliability coefficient (i.e. internal reliability) of $0.850,0.822$ and 0.839 Cronbach's alpha respectively (Nunnally and Bernstein, 1994). The 
Table IV AM in-house facilities related questions and respondents' responses (per construct)

\begin{tabular}{|c|c|c|c|c|c|c|c|c|}
\hline \multicolumn{9}{|c|}{$\begin{array}{c}\text { AM IN-HOUSE FACILITIES - SUB-SECTION } 4 \\
\text { Liker Scale: 1: Strongly Disagree 2: Disagree 3: Neutral 4: Agree 5: Strongly Agree }\end{array}$} \\
\hline & & $1(\%)$ & $2(\%)$ & $3(\%)$ & $4(\%)$ & $5(\%)$ & $M(\%)$ & SD (\%) \\
\hline \multicolumn{9}{|c|}{ Construct 1: Acquisition of in-house AM facilities \& establishment of 3D printing Lab } \\
\hline 4.1 & \multicolumn{8}{|c|}{ Acquisition of in-house AM/3D printing facilities at the university fosters: } \\
\hline $4.1 \mathrm{a}$ & Effective AM education & 0 & 1.5 & 4.6 & 51.5 & 42.3 & 4.35 & 0.644 \\
\hline $4.1 \mathrm{~b}$ & Effective AM research & 0 & 1.5 & 4.6 & 54.6 & 39.2 & 4.32 & 0.635 \\
\hline 4.2 & $\begin{array}{l}\text { Establishment of AM/3D printing labs } \\
\text { at the university would increase } \\
\text { students' interest in AM or } 3 \mathrm{D} \text { printing } \\
\text { technology }\end{array}$ & 0 & 0 & 4.6 & 55.4 & 40.0 & 4.35 & 0.569 \\
\hline \multicolumn{9}{|c|}{ Construct 2: Cutting-edge $A M / 3 D$ printing facilities at the university } \\
\hline 4.3 & \multicolumn{8}{|c|}{ A cutting edge in-house $A M / 3 D$ printing facilities at our university supports: } \\
\hline $4.3 a$ & Teaching & 0 & 1.5 & 7.7 & 58.5 & 32.3 & 4.22 & 0.647 \\
\hline $4.3 b$ & Learning & 0 & 2.3 & 6.9 & 60.0 & 30.8 & 4.19 & 0.660 \\
\hline $4.3 c$ & Academic research & 0 & 0.8 & 3.8 & 60.0 & 35.4 & 4.30 & 0.579 \\
\hline $4.3 d$ & Industry collaboration & 0 & 0 & 4.6 & 56.9 & 38.5 & 4.34 & 0.565 \\
\hline \multicolumn{9}{|c|}{ Construct 3: Effectiveness of available/existing AM facilities } \\
\hline 4.4 & \multicolumn{8}{|c|}{ In-house AM facilities at selected universities in South Africa are available for students and academics: } \\
\hline $4.4 a$ & For design and prototyping purposes & 0 & 2.3 & 10.0 & 50.8 & 36.9 & 4.22 & 0.718 \\
\hline $4.4 \mathrm{~b}$ & For final product printing purposes & 0 & 3.8 & 11.5 & 48.5 & 36.2 & 4.17 & 0.779 \\
\hline $4.4 c$ & $\begin{array}{l}\text { For teaching and research activities (i.e. } \\
\text { master's and PhD students research) }\end{array}$ & 0 & 3.8 & 14.6 & 50.0 & 31.5 & 4.09 & 0.782 \\
\hline $4.4 d$ & For final or fourth year projects & 0 & 5.4 & 13.1 & 54.6 & 26.9 & 4.03 & 0.787 \\
\hline
\end{tabular}

Kaiser-Meier-Olkin (KMO) for this sub-section is 0.785 which measures the sample adequacy and exceeds the "acceptable good value" of 0.70. To test if the correlations between items are higher enough, the Bartlett's test of sphericity is approx. chi-square 671.181 and reached statistical significance of $(p<0.000)$. The questions in the first construct focused on the "acquisition of in-house $\mathrm{AM} / 3 \mathrm{D}$ printing facilities and the establishment of $3 \mathrm{D}$ printing lab" at the universities. The questions aimed to examine the respondents' view as relating to the acquisition of $A M$ facilities at the universities and the need to launch modern AM/3D printing lab such as (Idea 2 Product lab) at the university to promote effective AM education and research.

The questions in the second construct centered on the "cutting-edge AM facilities at the university" as a tool to support teaching, learning, academic research and industry collaboration. The questions in the second construct aimed to examine to which extent is the availability of $\mathrm{AM} / 3 \mathrm{D}$ printing facilities at the universities serve as a tool to promote AM education. The feedback shows that the majority of the respondents strongly agreed to the questions shown in Table IV. The third construct contained questions on the "effectiveness of the available or existing AM/3D printing facilities at the university". The questions within the third construct aimed to examine respondents' views as relating to the accessibility of the existing AM facilities at the universities for students and academics use. Based on the respondents' feedback, this shows that the respondents agreed that the existing AM facilities at the selected universities in South Africa are accessible and very useful for both the students and academics. On the other hand, the questions within the construct also have high "neutral" responses which imply that some respondents did not fully agreed with the questions.

The inter-items correlation matrix for the three constructs is statistically significant at the level $0.7,0.5$ and 0.5 respectively. The inter-items correlation matrix contained no negative values which imply that all the items measured same underlying characteristics (Pallant, 2011). The relationship between the first and second constructs considered to be "medium" with component correlation coefficient of 0.303 , which implies that there is practically visible relationship. The relationship between second and third construct regarded to be "small" with component correlation coefficient of 0.165 and this indicates no practical significant relationship.

\subsubsection{Descriptive statistical analysis - additive manufacturing research and development}

The questions in this sub-section centered on the "Research and Development (RED in $A M$ )" as presented in Table V. These questions aimed to examine the importance of $\mathrm{R} \& \mathrm{D}$ in promoting $\mathrm{AM}$ technology in the education sector, i.e. within the university environment. The construct exhibited an internal reliability of 0.824 Cronbach's alpha which is considered an acceptable reliability coefficient (Nunnally and Bernstein, 1994). The KaiserMeier-Olkin (KMO) for this sub-section is 0.812 which measures the sample adequacy and exceeds the "acceptable good value" of 0.70. To test if the correlations between items are high enough, the Bartlett's test of sphericity is approx. chi-square 262.779 and reached statistical significance of $(p<0.000)$. The questions in the construct centered on the "contributing factors towards effective research and development in AM". The responses received shows that research and development is playing significant roles in creating $\mathrm{AM}$ standard, $\mathrm{AM}$ patent and in advancing new 
Table V AM Research and development related questions and respondents' responses (per construct)

AM RESEARCH AND DEVELOPMENT (R\&D) - SUB-SECTION 5

Liker Scale: 1: Strongly Disagree 2: Disagree 3: Neutral 4: Agree 5: Strongly Agree

$1(\%) \quad 2(\%) \quad 3(\%) \quad 4(\%) \quad 5(\%) \quad M(\%) \quad S D(\%)$

Construct: Contributing factors towards effective Research and Development (R\&D) in AM

5.1 Advancement of AM; Research and development is playing vital roles:

5.1a In the creation of AM standards (ISO/ASTM)

5.1b For registration of AM patent

5.1.c For innovative and technological advancement of AM

5.2 Inclusion of a MSc program in AM at selected universities in South Africa would further strengthen AM Research and Development at the universities

5.3 Annual fund and grant from the Department of Science and Technology (DST) would boost AM research output at various universities in South Africa

5.4 Annual fund and grant from National Research Foundation (NRF) increase AM research output at various universities in South Africa

$\begin{array}{llrllll}0 & 1.5 & 15.4 & 56.9 & 26.2 & 4.08 & 0.689 \\ 0 & 0 & 14.6 & 59.2 & 26.2 & 4.12 & 0.630 \\ 0 & 0 & 7.7 & 63.1 & 29.2 & 4.22 & 0.570 \\ 0 & 0 & 15.4 & 54.6 & 30.0 & 4.15 & 0.660 \\ 0 & 0 & 6.9 & 53.8 & 39.2 & 4.32 & 0.600 \\ 0 & 0 & 4.6 & 46.9 & 48.5 & 4.44 & 0.584\end{array}$

innovation. More so, the respondents' feedback indicates that inclusion of an MSc programme in AM will further strengthen research and development of AM at the universities. Based on a significant number of positive responses the questions on "inclusion of MSc program in Additive Manufacturing". Therefore, this study proposed that a postgraduate program (i.e. MSc or M.Eng) in AM should be introduced to South African universities offering engineering degree to further strengthen the research activities in the field of $\mathrm{AM}$ and which in return will increase the number of AM personnel/professionals. In this construct, the inter-item correlation matrix is statistically significant at the level 0.20 (Piedmont, 2014). The inter-item correlation matrix in this construct shows that all the items measured same underlying characteristics.

\subsection{Open-ended questions responses}

This is a voluntary section with the aim to gain more insights feedback from the respondents. This section contained two open-ended questions as stated below. Some of the respondents' feedback could be linked to the five factors contained in the main body of the questionnaire.

First open-ended question: Do you think inclusion of AME to science and engineering curriculum at South African universities is a good idea?

In the first open-ended questions, out of 130 participants in the survey, only 40 respondents attempted to answer the question as expected. 30 respondents indicate "Yes"; 20 respondents indicate " $\mathrm{N} / A$ " (i.e. not applicable). In this case, "Yes" as an answer implies that the respondents supported the "the inclusion of AM education to science and engineering curriculum at South African universities". The "N/A" also indicates that some respondents were neutral to the question. From the 40 respondents that completed the first open-ended question, some of the feedback were alike in their construction and to avoid unnecessary repetitions, only key feedback were captured and summarized in Table VI.

The feedback in Table VI provides more insights into the first open-ended question and these can also be linked to the five sub-sections of the main body of the questionnaire. The summary of the respondents' feedback shows that the inclusion of AM education in the education curriculum at the SA universities would:
- allow collaboration with other fields;

- increase AM awareness;

- enhance STEM education;

- assist towards the actualization of Industry 4.0;

- increase in the number of AM professionals;

- encourage people to pursue career in AM;

- improve students' engineering drawing skills;

- expose people to AM; and

- promote technological advancement in AM.

Second Open-Ended Question: Does the "Idea 2 Product (I2P) Lab at VUT" and "Pukke $3 \mathrm{D}$ Printing Centre" at NWU or the $3 \mathrm{D}$ printing Lab at your university is having positive impacts on Additive Manufacturing education or Promoting AM education?

The essence of the second open-ended question is to provide the respondents with ability to express their view voluntarily as relating to the positive impacts of the $\mathrm{AM} / 3 \mathrm{D}$ printing lab at their universities. 45 respondents attempted the question indicates "Yes", and 10 respondents indicated "N/A" while 30 respondents did not attempt to answer the question. In this case, "Yes" implies that the respondents supported or agreed with the question that " $3 \mathrm{D}$ printing lab at the university is having positive impacts on $A M$ education or promoting $A M$ education" while " $\mathrm{N} / A$ " implies some of the respondents are neutral to the question.

Table VII presents the summary of the key feedback from the respondents and excluded the responses that are alike in its sentence construction.

The overall summary of respondents' feedback to the second-open-ended question indicates that the available AM/ $3 \mathrm{D}$ printing lab at the selected universities in SA are:

- assisting students to building career in AM;

- improving students' engineering drawing skills;

- providing students with fundamental knowledge of AM;

- equipping students with the ability to work as a team on a project and research;

- promoting innovative and technological research in AM; and

- increasing AM personnel or graduates in the field of AM.

\section{Stated hypotheses for the study}

The nature of this study requires a number of hypotheses to be stated. Therefore, the null hypotheses $(\mathrm{HO})$ and alternative 
Table VI Summary of the key respondents' feedback to the first open-ended question

\section{S/N Key Summary of the Respondents' Feedback}

1. Yes, I do, I also feel that the arts should not be ignored as innovation happens best when different field collaborate

2. It is a good idea and it will help students to understand AM technology and advanced in this field

3. Yes, most of the science and engineering students are not being aware of AM technology

4. There is a need for South African universities to include AM in their educational curriculum

5. Yes, Inclusion of AM education to STEM education is necessary at this era of Industry 4.0

6. This is a good idea, it will promote AM education and expose students to AM technologies

7. The inclusion of $A M$ education at $S A$ universities will improve mechanical engineering degree curriculum

8. Yes, this will greatly provide significant advantage to science and engineering curriculum in SA

9. I think the inclusion of AM education in the science and engineering curriculum in SA is a good idea towards Industry 4.0 revolution in the country

10. It will help students, academics and industry professionals to develop interest in AM technology and pursue career in AM

11. AM education is very important at the universities because of the technological advancement in the world and it will improve students' knowledge of design within the engineering curriculum or degree

12. To take AM technology into another height in STEM education, its inclusion in the educational curriculum is inevitable

13. Awareness of AM technology is growing rapidly, and specific AM courses can be developed and included in the educational system at the university and this will increase the awareness of the technology

14. AM/3D printing technology has been identified as a potential game changer for Industry 4.0 and in preparing graduate that will take over the AM industry is very essential, and inclusion of AM education in STEM curriculum is a good idea

15. Yes, the educational aspect of the technology will encourage students to do more critical thinking and will attract more students to study STEM courses and career

16. I think inclusion of AM education is a good idea but should start at a much lower educational level; for example, early high school

17. Yes, inclusion of AM education will enhance the knowledge and understanding of engineering principles in the industry

18. Yes, to include AM education is a good idea, but it must be within the South Africa STEM education context

19. My fourth-year project is on AM technology and if such technology can be included in the SA education curriculum, it will go a long way in assisting fourth years' student to carry out research in AM field

20. If AM education can be incorporated into STEM education in SA, it will be a good achievement for SA universities

21. Yes, it will give students an idea of what is really happening in the AM industries when AM course is included as part of university curriculum

22. Yes, inclusion of AM education will make student compete with other countries not just technology but production and economic growth as well

23. Yes, it is a good idea and it makes the learning process to be easy and understandable

24. Yes, inclusion of AM education will assist students to keep up with the changing of technology in the world

25. Yes, AM education will provide students with knowledge of AM and this will assist both the undergraduate and postgraduate students when working on project or research related to AM

26. Yes, I didn't have an idea of what AM mean, until I started working at the VUT. The students in the university needs exposure to AM to gain knowledge and interest in AM and before getting to the industry

27. Yes, from my personal point of view, I have noticed that most of the students who visited our AM lab have no idea or little knowledge of what AM technology. The inclusion of AM education in the university's STEM curriculum will be good

28. Yes, because both undergraduate and postgraduate students need exposure AM technology

29. Yes, inclusion of AM course is the only platform to introduce AM education to the South African universities

30. Yes, for SA government to benefit from their investments on AM technology, there is a need to introduce AM education in the STEM educational system in $S A$

hypotheses (H1) are listed below which are based on the five factors used in the questionnaire.

1 AM Technology

H0. AM technology is enhancing the science and engineering education at the universities and having positive impacts across many industries.

H1. AM technology is not enhancing the science and engineering education at the universities and not having positive impacts across many industries.

\section{AM Technology Transfer}

H0. Technology transfer is playing a significant role in promoting AM education and creating an enabling environment for university-industry collaboration.
H1. Technology transfer is not playing a significant role in promoting AM education and does not creating an enabling environment for university-industry collaboration.

\section{AM Educational Curriculum}

HO. Inclusion of $A M$ educational curriculum at the university is necessary to increase AM personnel or professionals; to strengthen students' interest and creates career path in AM.

H1. Inclusion of $A M$ educational curriculum at the university is not necessary to increase AM personnel or professionals; to strengthen students' interest and creates career path in AM. 
Table VII Summary of the key respondents' feedback to the second open-ended question

\begin{tabular}{|c|c|}
\hline $\mathrm{S} / \mathrm{N}$ & Key Summary of the Respondents' Feedback \\
\hline 1. & It is making great impact on AM education and assisting student to build career path in AM \\
\hline 2. & The Idea 2 Product at VUT is making positive impact and promoting AM knowledge among interested students \\
\hline 3. & $\begin{array}{l}\text { The NWU Pukke } 3 \mathrm{D} \text { printing centre is assisting students to bring their creative thinking into reality, therefore the lab is making positive } \\
\text { impact }\end{array}$ \\
\hline 4. & The $3 \mathrm{D}$ printing facilities at our university is making positive impact and enhancing students' innovative skills \\
\hline 5. & The AM facilities at the lab provides excellent hands-on-experience of AM technology to students \\
\hline 6. & The $3 \mathrm{D}$ printing lab is helping postgraduate students to carry out innovative and technological research in AM \\
\hline 7. & The $12 \mathrm{P}$ lab at VUT assisted students with different design projects but the I2P lab can be expanded to accommodate more students \\
\hline 8. & $\begin{array}{l}\text { The } 3 \mathrm{D} \text { printing lab at the university is having great impacts on students and making the students to "think additive", i.e. to be innovative } \\
\text { and creative in thinking }\end{array}$ \\
\hline 9. & $\begin{array}{l}\text { The } 3 \mathrm{D} \text { printing lab at the NWU is changing the teaching and learning perspective of the students as the students engaging in design of } \\
\text { prosthetic and other complex design. }\end{array}$ \\
\hline 10. & The $3 \mathrm{D}$ printing lab at VUT has introduced many students into the fundamental knowledge of AM \\
\hline 11. & $\begin{array}{l}\text { The positive impacts of Idea } 2 \text { Product lab at VUT is overwhelmingly as more people have gained knowledge about AM technology, but more } \\
\text { AM facilities and AM personnel are still needed }\end{array}$ \\
\hline 12. & My advice is that such I2P lab should be established on every university campus in SA because of its positive impact on students. \\
\hline 13. & $\begin{array}{l}\text { The } 3 \mathrm{D} \text { printing lab is having positive impact on AM education and it is preparing tomorrow engineers and scientist to take over the } \\
\text { manufacturing workforce challenges and provide solution }\end{array}$ \\
\hline 14. & $\begin{array}{l}\text { An in-house AM equipment is an essential aspect in promoting AM education at the universities. Some universities don't have 3D printing } \\
\text { lab for students' use per se, it would be good if } 3 \mathrm{D} \text { printing lab like } 12 \mathrm{P} \text { can be established }\end{array}$ \\
\hline 15. & $\begin{array}{l}\text { As more AM personnel and graduates with knowledge of AM are needed globally, establishment of AM lab such as I2P lab will increase the } \\
\text { potentiality of the students developing interest in AM }\end{array}$ \\
\hline 16. & $\begin{array}{l}\text { The } 3 \mathrm{D} \text { printing lab is very useful for engineering students because people are getting expose to AM technology and they are becoming } \\
\text { sound technological }\end{array}$ \\
\hline 17. & AM lab has enabled students to change their view about engineering drawing and design in a more positive way \\
\hline 18. & The AM lab helps students to practice what they learn in theory using the available AM facilities at the university \\
\hline 19. & $\begin{array}{l}\text { The I2P lab is making significant impact in the life of the willing students because the lab is accessible to everyone irrespective of your course } \\
\text { of study }\end{array}$ \\
\hline 20. & $\begin{array}{l}\text { The 3D printing lab is having positive impact on students but most of the lab are equipped with entry-level 3 D printing machines, and the } \\
\text { high-end industrial AM machines should be introduced to the laboratory as well }\end{array}$ \\
\hline 21. & $\begin{array}{l}\text { The } 3 \mathrm{D} \text { printing lab impact can be felt on science and engineering education through effective use of CAD software by the students most } \\
\text { especially among mechanical engineering degree students }\end{array}$ \\
\hline 22. & The use of $3 \mathrm{D}$ printing facilities by the students has promote effective team work on design assignment or project \\
\hline 23. & $\begin{array}{l}\text { The lab contained entry-level } 3 \mathrm{D} \text { printers for teaching basic AM technology and through this platform students are being equipped to } \\
\text { develop a mind-set that would advance their career }\end{array}$ \\
\hline 24. & $\begin{array}{l}\text { The AM lab at my university comprises of fewer entry-level } 3 \mathrm{D} \text { printers for students and staffs use; the lab is contributing meaningful to the } \\
\text { advancement of AM education, but more } 3 \mathrm{D} \text { printers are needed to accommodate more people }\end{array}$ \\
\hline 25. & $\begin{array}{l}\text { The AM/3D printing lab allows first year students to develop interest in AM and grow to become an AM expert at their fourth years/ } \\
\text { postgraduate level; the primary aim of AM lab is to promote AM education at the university }\end{array}$ \\
\hline
\end{tabular}

\section{AM In-House Facilities}

H0. Availability of cutting-edge AM facilities would promote effective AM education and advances AM research activities at the universities.

H1. Availability of cutting-edge AM facilities would not promote effective AM education and advance AM research activities at the universities.

\section{$5 A M$ Research and Development (RED)}

H0. Research and development creates room for innovative and technological advancement in AM through various funding from different government bodies (e.g. DST, NRF, etc.).
H1. Research and development does not create room for innovative and technological advancement in AM through various funding from different government bodies (e.g. DST, NRF, etc.).

\subsection{Hypotheses testing}

To truly test for the hypotheses in this study, certain sets of statistical parameters were considered, for instance, P-value, statistical significance $(P)$, effect size, etc. The null and alternative hypotheses have been stated above and irrespective of the alpha level, the hypotheses are tested based on two outcomes, i.e. Reject null hypothesis (if the statistical significance is $p$-value $<=0.05$ ) and Fail to reject the null hypothesis (if the statistical significance is $p$-value $>0.05$ ) at 95 per cent confident interval (Martz, 2013). Typically, $p$-value is used to decide if the data support the null 
hypothesis or not, but in situation where the P-value is extremely low (i.e. below 0.05), from a statistician's point of view "the null hypothesis must go or rejected" (Martz, 2013). In this study, the hypotheses were based on a "two tailed significant testing" and the $t$-Test was carried out in relation to the gender of the respondents. An accepted significant level for two tailed hypotheses is alpha $(\alpha)=0.05$ and the two tailed hypotheses testing is based on $\mathrm{HO}$ : $P=$ alpha and H1: $P \neq$ alpha. The hypotheses were tested using significant $P$-value to determine where the data supported the null hypotheses or not as shown in Table VIII. The null hypotheses will be accepted when the $\mathrm{P}(\alpha)$ value $>=0.05$ and rejected when $\mathrm{P}$ $(\alpha)$ value $<=0.05$. All the significant $P$ values were $>$ than $\alpha=$ 0.05 . Therefore, all the null hypotheses $(H O)$ were accepted, and all the alternative hypotheses $(H 1)$ were rejected.

\section{Proposed framework for effective additive manufacturing education}

This section contains the proposed "Framework for Additive Manufacturing Education at the Universities. The five factors used in the questionnaire formed the foundation for the proposed framework as shown in Figure 9. It is expected that these key factors or variables would work together if carefully implemented at the universities. The framework is uniquely or universally designed to suit any university that attempting to embark on AM education journey i.e. it is not only applicable to South African universities, but other universities globally can adopt or adapt the proposed AM education framework suit their education/university system. The framework cannot work in isolation of each other; each factor has a significant role to play in the actualization of $\mathrm{AME}$ at the university level. For instance, AM education cannot exist without the AM as a technology, while AM technology transfer creates an enabling environment for university-industry collaboration. The next sub-sections briefly discussed the five factors contained in the proposed framework for effective AM education at the universities - a case of South African universities.

\subsection{Additive manufacturing technology}

AM technology is the first and most significant factor to be considered in the proposed framework for AM education as

Table VIII The outcomes of the hypotheses testing

\begin{tabular}{|c|c|c|c|c|}
\hline AM framework factors/Variables & The significant $(P)$ & Null hypothesis $(\mathrm{HO})$ & Alternative hypothesis $(H 1)$ & Effect size \\
\hline \multicolumn{5}{|l|}{ 1. AM Technology } \\
\hline Construct 1 - Applications/usefulness of AM technology & $P(0.627)$ value $>0.05$ & Accepted & Rejected & 0.085 \\
\hline Construct 2 - Importance \& advantages of AM technology & $P(0.137)$ value $>0.05$ & Accepted & Rejected & 0.255 \\
\hline $\begin{array}{l}\text { Construct } 3 \text { - Present \& future impacts of AM technology on } \\
\text { science and engineering education }\end{array}$ & $P(0.046)$ value $>0.05$ & Accepted & Rejected & 0.354 \\
\hline $\begin{array}{l}\text { Construct } 4 \text { - Accessibility and acquisition of fundamental } \\
\text { knowledge of AM technology }\end{array}$ & $P(0.363)$ value $>0.05$ & Accepted & Rejected & 0.154 \\
\hline \multicolumn{5}{|l|}{ 2. AM Technology Transfer } \\
\hline $\begin{array}{l}\text { Construct } 1 \text { - Aim, roles and importance of technology } \\
\text { Transfer }\end{array}$ & $P(0.598)$ value $>0.05$ & Accepted & Rejected & 0.090 \\
\hline $\begin{array}{l}\text { Construct } 2 \text { - Benefits of University-Industry collaboration } \\
\text { in AM technology transfer }\end{array}$ & $P(0.637)$ value $>0.05$ & Accepted & Rejected & 0.082 \\
\hline $\begin{array}{l}\text { Construct } 3 \text { - Involvement of } 3 \text { D Printing service bureau or } \\
\text { company in AM technology transfer }\end{array}$ & $P(0.863)$ value $>0.05$ & Accepted & Rejected & 0.030 \\
\hline \multicolumn{5}{|l|}{ 3. AM Educational Curriculum } \\
\hline $\begin{array}{l}\text { Construct } 1 \text { - Need for more AM personnel in the field of } \\
\text { AM }\end{array}$ & $P(0.553)$ value $>0.05$ & Accepted & Rejected & 0.105 \\
\hline $\begin{array}{l}\text { Construct } 2 \text { - Inclusion of AM education/course in science } \\
\text { and engineering curriculum }\end{array}$ & $P(0.945)$ value $>0.05$ & Accepted & Rejected & 0.012 \\
\hline $\begin{array}{l}\text { Construct } 3 \text { - Suitability of entry-level } 3 \text { D Printer for AM } \\
\text { education }\end{array}$ & $P(0.984)$ value $>0.05$ & Accepted & Rejected & 0.003 \\
\hline \multicolumn{5}{|l|}{ 4. AM In-House Facilities } \\
\hline $\begin{array}{l}\text { Construct } 1 \text {-Acquisition of in-house AM facilities \& } \\
\text { establishment of } 3 \text { D printing lab }\end{array}$ & $P(0.269)$ value $>0.05$ & Accepted & Rejected & 0.195 \\
\hline $\begin{array}{l}\text { Construct } 2 \text { - Cutting-edge AM/3D printing facilities at the } \\
\text { university }\end{array}$ & $P(0.322)$ value $>0.05$ & Accepted & Rejected & 0.168 \\
\hline Construct 3 - Effectiveness of the available/existing AM & $P(0.618)$ value $>0.05$ & Accepted & Rejected & 0.086 \\
\hline
\end{tabular}

Facilities

\section{AM Research and Development (R\&D)}

Construct - Contributing factors towards effective research $P(0.607)$ value $>0.05$ Accepted and development (R\&D) in AM 


\section{Micheal Omotayo Alabi et al.}

Figure 9 The proposed framework for effective AME

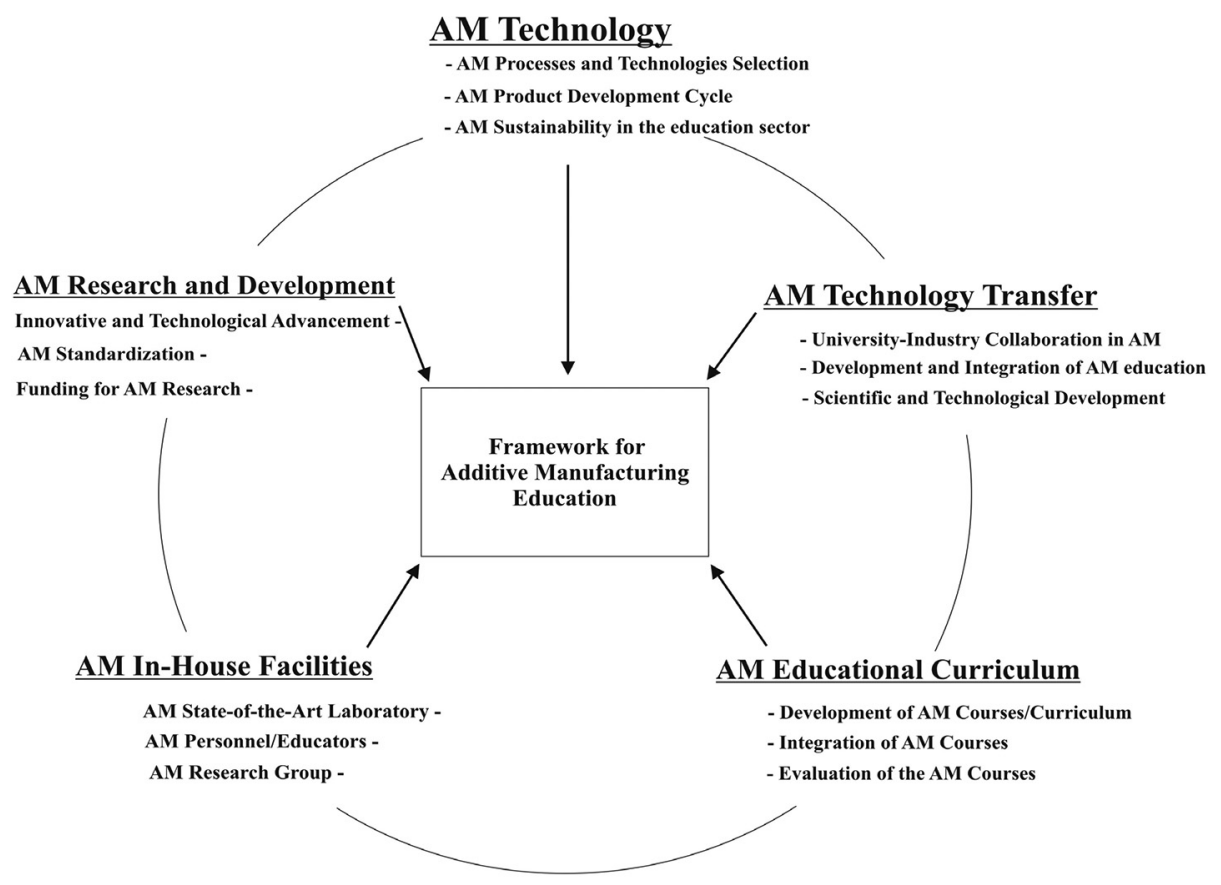

Source: Researcher's own construction

shown in Figure 9. AM technology is regarded as one of the twenty-first century advanced manufacturing technologies. In the past few years, more emphases have been placed on the inclusion of AM technologies across all level of education in South Africa. More so, during a stakeholder workshop in 2013, education was identified as key priorities to have an effective adoption of AM technology in South Africa. In 2016, the National Forum on AM education and training addresses the need to adapt AM technologies into the engineering and manufacturing education which will serve as a platform to advance AM (Zelinski, 2016). The following supporting subfactors described below will enable AM technology to play significant role:

\subsubsection{Additive manufacturing processes and technologies selection.}

This is a fundamental approach to consider when introducing $\mathrm{AM}$ technologies into the education sectors, that is, what type of AM processes (powder-based or Liquid-based) and AM technologies (e.g. Selective Laser Sintering, Fused Deposition Modelling) would be applicable to the AM research group or $\mathrm{AM}$ lab at a particular university. Appropriate AM machines with suitable AM technology will enhance productivity and improve teaching and learning processes at the universities.

\subsubsection{Additive manufacturing product development cycle}

The AM product development cycle is the process of producing final $3 \mathrm{D}$ printed products, i.e. starting from the concept design to prototype (using CAD software) and production of the final parts. Irrespective of the types of $A M$ processes or $A M$ technologies classification chosen, the product development cycle is the same. The product development cycle is a fundament aspect of AM technology. In this regard, a suitable $\mathrm{AM}$ system for the educational sector should be the type that can be operated easily and understood quickly by the students within a short period of time. This would assist AM beginners to develop interest in the technology speedily.

\subsubsection{Additive manufacturingsustainability}

The sustainability of AM education is a paramount factor to be considered when introducing $\mathrm{AM}$ technologies into the education sector. AM technology is a new advanced manufacturing technology that requires feasible sustainability strategy. Despite the advantages of AM technology, there are still some sustainability issues to look into such as materials reuse, environmental impacts, cost of production, AM supply chain, AM lab maintenance cost, introduction and amendment of AM curriculum, etc. (Ford and Despeisse, 2016). Introduction of AM education at the university requires a longterm sustainability strategy or planning to support continuous improvement.

\subsection{Additive manufacturing technology transfer}

To promote an effective AM education at the university, technology transfer would play an important role. Lenagh (2012) stated that "technology transfer requires a proactive approach that combines engaging researchers, promoting the technology and encouraging potential industrial partners to use the particular technology". Transfer of technology (TOT) is through a licence agreement that allows the university to retain the ownership of the intellectual property and the industrial partner as well receives conditional right to use and develop the technology (Lenagh, 2012). AM technology transfer could serve as a platform to transfer fundamental theoretical knowledge and hands-on-experience of AM processes and technologies to a wider user [students, academics and industry professionals] through wider collaboration between the 
universities and industrial sector in AM. The following subfactors or characteristics would help when considering AM technology transfer in the education sector:

8.2.1 University-industry collaboration in additive manufacturing To further enhance and revolutionize the education aspect AM and to prepare graduate for future job in AM industry, university-industry collaboration is very essential in this regard. Technology transfer creates an enabling environment to incorporate the students, academics and industry partners in AM together. This will increase industry and university collaboration in AM research. In a situation where the universities could not afford Industrial AM machines, university-industry collaboration would give opportunity for students and academics to use their AM machine to carry out advanced AM related research. These would lead to improve AM product quality and product performance. More so, University-Industry collaboration brings potential business opportunities such as mass customization of AM product (Huang et al., 2015).

\subsubsection{Development and integration of additive manufacturing education}

The development and integration of AM education at the university involves certain level of expertise from both the university and industry. The university academics can provide theoretical knowledge and certain level of practical experience, while the industry experts can provide practical insight or knowledge of AM technology from an industrial perspective. Therefore, both the university's academics and industry experts have significant role to play in developing an effective AM education system at the university. A successful integration of AM education at the university would increase the theoretical and practical skills of AM technology for the students.

\subsubsection{Scientific and technological development}

Technology transfer promotes scientific and technological innovation at both the university and industry. AM technology is still at the infant stage of development and possible ways to sustain and promote this disruptive technology is through intensive scientific discovery and technological innovation within the education system. AM is a type of technology that encourages both creative and innovative thinking. The university can serve as a platform to instill such thinking in students, academics and industry professionals through effective AM education.

\subsection{Additive manufacturing educational curriculum}

Development of suitable and feasible education curriculum in $\mathrm{AM}$ is the most essential part of the proposed framework for AM education. Significant growth in the use of $A M / 3 D$ printing technologies across different sectors have created high demand for more skilled workforce of scientists, engineers, engineering technologists with proficient knowledge of AM processes to execute $3 \mathrm{D}$ design projects from software $3 \mathrm{D}$ design to delivery of physical $3 \mathrm{D}$ printed parts using worldclass AM machines (Bal and Abatan, 2017). Some recent studies have made strong emphases on the need to include educational curriculum in $\mathrm{AM}$ for science and engineering degree at the university (Minetola et al., 2015; Bal and Abatan,
2017; Dickens et al., 2016; Colletti, 2016; Gatto et al., 2015; Go and Hart, 2016; Williams and Seepersad, 2012; Radharamanan, 2017). Jesse Roitenberg from Stratasys, Inc, a leading manufacturer of $3 \mathrm{D}$ printing system stated that "incorporating $\mathrm{AM} / 3 \mathrm{D}$ printing into the Higher Education Institutions curriculum would assist in preparing students/ future engineers for a successful career path in STEM" (Roitenberg, 2016). The following sub-factors/characteristics would contribute to a successful incorporation of $\mathrm{AM}$ educational curriculum at the university:

\subsubsection{Development of additive manufacturing course/curriculum}

An important approach to AM education at the university and a first step to a successful integration of $\mathrm{AM}$ educational curriculum is to develop an AM course/curriculum within the context of the country educational system. Already, some universities across USA, Europe and China have incorporated AM course into their engineering degree curriculum at the university. For example, Miami University has integrated AM education into their engineering technology curriculum with the aim to provide students with adequate hands-on-experience using AM laboratory. According to Bal and Abatan (2017):

The educational institutions need to design new courses or revise existing courses with hands-on laboratory components in order to introduce their students to AM technology and teach them how to design customized and complex products for current and future applications of AM using modern $3 \mathrm{D}$ printers

Development of a new course in AM entails some certain knowledge and expertise of AM technology. In some cases, existing STEM courses can be re-designed to conform to AM curriculum at the university. The AM course can be developed as a full semester course for both undergraduate and postgraduate students to prepare them for workforce skills in AM technologies. Short-course program can be develop for professionals in the industry to get exposure to $\mathrm{AM}$ technologies and gain hands-on-experience needed to complement their existing manufacturing technologies or systems.

\subsubsection{Integration of additive manufacturing courses}

One aspect of AM education is to develop AM courses and another crucial aspect is the integration of the courses into the existing educational system either as a new AM courses or in addition to the current STEM courses. Appropriate integration methods have to be considered, for instance, integrating $\mathrm{AM}$ course into the engineering curriculum, the design and manufacturing skills should be the central focus. This means that the students must understand how $3 \mathrm{D}$ printing work, learn how to design objects using some entry-level $3 \mathrm{D}$ CAD software tools and gain basic repair techniques of $3 \mathrm{D}$ printing. $\mathrm{AM} / 3 \mathrm{D}$ printing designs and Engineering drawing is expected to assist the students to improve their engineering skills (Shaw, 2017).

The AM course can be integrated directly into the education curriculum after careful consideration or selection of relevant course topics. The integration can be done in parallel with the existing STEM curriculum, i.e. AM course can be introduced gradual into the educational system by re-structuring one or two existing educational curriculum that are closely related to design and manufacturing. Furthermore, Thurn et al. (2017) also proposed other AM courses integration approach that: 
$\mathrm{AM} / 3 \mathrm{D}$ printing could be taught effectively if the theoretical approach can be skipped and the students can proceed into the real complex task of AM technology from the beginning which would lead to very fast results and follow by 'brail trail and minor error

Thurn et al (2017) considered this approach as quite a rough integration approach but believes that the students/learners would want to improve their skills and consequently become the driving force in AM field.

\subsubsection{Evaluation of the additive manufacturing course}

To ensure effective AM educational curriculum, progressive evaluation of the course is very essential. As part of sustainability measures towards AM education at the university, there is a need to measure the continuous progress of AM curriculum and make appropriate amendment when necessary. In May 2015, Thurn et al (2017) developed an AM educational concept for training people the fundamental of AM using mobile AM laboratory facilities. Between May 2015 and December 2016, an internal evaluation was performed to measure the progress of the AM training and to ascertain that they have indeed covered the target population. The outcomes of the evaluation show that to meet the need of various target group; new AM teaching/course need to be developed depending on the participants' experiences and desired learning intentions. The University of Wollongong in Australia introduced AM course to final year students in the school of mechanical, materials and mechatronics; called "MECH $482-$ Introduction to Additive Manufacturing" using project-based learning. The MECH 482 course was evaluated to find out the effectiveness of the AM teaching. Students' provide feedback as relating to their experiences with the course which shows that they gained both theoretical and practical knowledge of AM. The evaluation also indicated that the course content was set too low for a final year course. As a result of this, the course was amended to meet the suitable standard for a final year degree (Harvey, 2016). Therefore, evaluation of AM course should be a continuous process to ascertain quality and continuous improvement of AM educational curriculum at the university.

\subsection{Additive manufacturing in-house facilities}

There is no institution that can successful introduce or integrate AM technologies into their education systems without state-of-the-art in-house AM/3D printing facilities. Availability of $\mathrm{AM} / 3 \mathrm{D}$ printing facilities at the university would determine the level of teaching, learning and research activities in the field of AM. Most developing countries are currently not considering AM education due to unavailability of AM facilities for education and research purposes. For instance, in South Africa, "only approximately two-third of the universities have $\mathrm{AM}$ equipment in-house, and approximately a quarter of the universities also pursue AM as a research field" (RAPDASA, 2018). Waseem et al. (2016) recommended that engineering and technology universities should acquire $\mathrm{AM} / 3 \mathrm{D}$ printing inhouse facilities to assist students in transforming innovative ideas into physical reality. The AM in-house facility is an important aspect of AM education journey at any institution to facilitate efficient knowledge transfer. Waseem et al. (2016) further stresses that establishment of $\mathrm{AM} / 3 \mathrm{D}$ printing lab at the universities will serve a platform to introduce AM education. $\mathrm{AM}$ equipment in-house at the university would increase cutting edge research activities and enhances STEM education.
The following sub-factors/characteristics would help when considering AM in-house facilities within the education sector or within the university environment:

\subsubsection{Additive manufacturing state-of-the-art laboratory}

In recent times, some of the AM centers are called "centre of excellence in additive manufacturing" or "additive manufacturing centre for advanced manufacturing". This shows that "excellence" is very important in planning AM/3D printing laboratory. Acquisition of AM facilities require stateof-the-art laboratory to promote the use of AM technology at the higher educational institutions effectively. It is very essential to establish AM laboratory that would stimulate students to develop interest in AM technologies and motivate researchers to conduct research in emerging areas. One aspect AM journey at the university is to purchase range of world-class AM facilities, another important aspect is to have well-structured modern-day AM laboratory that would bring out the beautiful of the AM equipment. An example of such state-of-the art AM lab in South Africa is the Centre for Rapid Prototyping and Manufacturing (CRPM) at the Central University of Technology and the Additive Manufacturing Unit at the Vaal University of Technology, Sebokeng Campus.

\subsubsection{Additive manufacturing personnelleducators}

Functional AM laboratory requires experienced AM personnel/ educators or technologist. Acquisition of state-of-the-art AM equipment is not enough to bring about innovation and technological advancement in AM at the universities, rather it relies on well-experienced and expert AM operator/ technologist (Tess, 2017). More so, as many manufacturing industries finding it very difficult to secure engineering graduates with hands-on-experience or fundamental knowledge AM to take over job opening in this field as seen in Colletti (2016) study. The main aim of the AM educator or personnel in $\mathrm{AM}$ lab is to equip students/academics/ professionals with fundamental and advance AM knowledge which will eventually produce more graduates in the field of AM.

\subsubsection{Additive manufacturing research group}

One of the main essences of AM in-house facilities at the universities or research institutes are to promote cutting-edge research in the field of AM. A research group consists of team of researchers or experts in a particular field of research and working together on specific research area. To successfully carry out research in the field of AM, there is a need to establish a committed research group that will focus on both the basic and advanced research in AM. Some of the researchers in the research group could facilitate or develop the AM curriculum and strengthen the AM teaching. Some universities across the USA, Europe, the UK, Asia and South Africa have established AM research group that would focus on emerging research area in AM. To proceed on AM education journey at the university, creating a research group will play significant factor for future growth of AM education and research activities at the universities worldwide.

\subsection{Additive manufacturing research and development} Research and development is a crucial part of many organizations and industries to challenge the status quo 
technologically through innovative products, which would eventually led to market expansion and product development (BuildProtos, 2017). For any university or research institute to make major breakthrough in a particular field, research and development unit is very necessary. In the field of $A M, R \& D$ supports innovative discovery. Some organizations such as (Pwc, Deloitte, IBM, Amazon) are supporting AM R\&D through the production of timely white papers and online publications, and thereby promoting AM technology and showcasing emerging research progress in AM field (Garth, 2016; Jürgen et al., 2013). AM is assisting both small and giant business players across different sectors to undertake research and development at a basic to intermediate level which are not possible using conventional manufacturing (BuildProtos, 2017). The following sub-factors stated below would support effective $R \& D$ program for $A M$ education at the university.

\subsubsection{Innovative and technological advancement}

$\mathrm{AM}$ is regarded as innovative technologies of twenty-first century which is complementing various existing technologies. Innovative and technological advancement in AM would allow multidisciplinary research and promote industrial and scientific development. In today's world, AM technology is creating an enabling environment for virtually everyone to "think additive", that is, ability to design quickly based on individual innovative and creative thinking, since "Real Innovation Comes from Within" (Makerstation, 2017). When considering AM education at the university, innovation and technological advancement should be at the forefront of the initiative or planning, which could lead to new products development to satisfy specific target market and would serve as a means of generating more fund for the university.

\subsubsection{Additive manufacturing standardization}

Standardization is one of the challenges facing AM technology progress. For AM to truly attain its full potential as an advanced manufacturing technology, some widely accepted comprehensive standards need to be developed; otherwise, mass adoption of AM technology would be hindered (Tilton et al., 2017). Effective research and development is crucial in advancing AM standardization and certification. Recently, as part of the efforts to achieve AM standardization, ASTM International (a global standards developer) launched two new centers of excellence in AM in partner with other organizations such as Auburn, NASA, EWI (a manufacturing technology innovator) and a United Kingdom based manufacturing technology centre. The aim of establishing the two new centers is to accelerate research and development, standardization, and innovation in the field of AM (Anthony, 2018). Therefore, AM standardization should be an essential part of an effective AM education framework at the university.

\subsubsection{Funding for additive manufacturing research}

Funding is a strong factor in promoting AM education and research activities at any university. The government funding bodies/agencies or publicly funders from different organizations should serve as the crusader to champion the continuous improvement or progress of AM technology at the university. For instance, in the United States, various government bodies (particularly, National Science Foundation, public entrepreneurs, etc.) are investing heavily in the field AM technology (Peña et al., 2015). In the United Kingdom, as at 2016, 250 different organizations have invested $£, 55$ million towards research in AM but majority of the fund comes from the Engineering and Physical Sciences Research Council (EPSRC) and Innovate UK Programme (Wu et al., 2017). Also, In South Africa, government agencies such as Department of Science and Technology, National Research Foundation and Industrial Development Corporation having been very instrumental in the advancement of AM technology both within the educational and industrial sectors. Therefore, government funding bodies/agencies have a key role to play in promoting research and development in the field of AM and to provide solid foundation for AM education at the universities worldwide.

\section{Conclusions, limitations and future study}

The main aim of the study is to investigate the impact of AM technology at selected universities and to develop a framework for effective AM education to further enhance the educational aspect of the AM technology at South Africa universities. At the time of writing this paper, there had been very few studies focusing on AM framework, and there are no studies on the development of a framework for AM education that uses actual data from case studies (or other research methodology) to describe or develop a framework for AM education at the university. More so, this study has been able to answer the research questions. Therefore, the first and most significant contribution of this study is the development of a framework for AM education at South African universities. The proposed framework identifies and describes the primary factors of a successful AM education framework at the university and explained how each factor work together to achieve a common goal. Moreover, the proposed framework includes sub-factors/ characteristics that would influence a successful AM education framework or implementation. This study has provided significant insight and adds to the state-of-the-art knowledge into AM education, technology and framework.

In this study, a number of limitations were identified and one of the limitations of this study is the sample size and although, this study has justified the sample size used as suitable and sufficient to answer the research questions and permits generalization of the research findings. However, the sample size may limit the generalizations of the findings; future research should use large sample size for purpose of generalization. More so, the case study for this study was limited to selected universities (VUT, NWU, UJ and WITS) within two provinces in South Africa. Therefore, future study should extend the case study to other South Africa universities with strong presence of AM in-house facilities and research group as well. The study is limited to a quantitative method; future study should incorporate both quantitative and qualitative research method. The proposed framework for AM education in this study contained only five factors derived from comprehensive literature reviews. The authors believe that irrespective of any existing or developed framework, there is always a need to further improve the existing framework. Future study in this area should improve the proposed framework by including some other factors considered to be suitable for AM education advancement at the university, such as (AM commercialization, $\mathrm{AM}$ project management, $\mathrm{AM}$ 
continuous improvement, etc.) and to provide useful insights into how the new factors can be properly integrated into the existing framework. In conclusion, this study does not include implementation processes/strategies for AM education framework; therefore, future research should include possible implementation processes/strategies.

\section{References}

Akinlabi, E. (2016), “Additive manufacturing advances in academia and teaching. A presentation at NSTF light-based technologies innovation forum", available at: www.nstf.org.za/ wp-content/uploads/2016/03/Akinlabi-slides.pdf (accessed 24 October 2018).

Alabi, M.O., De Beer, D. and Wichers, H. (2019), "Applications of additive manufacturing at selected South African universities: promoting additive manufacturing education", Rapid Prototyping fournal, Vol. 25 No. 4, doi: 10.1108/RPJ-08-2018-0216.

Anthony, C. (2018), “Auburn, partner organizations sign agreements for additive research centres", available at: www. eng.auburn.edu/news/2018/07/additive-signing-ceremonies. html (accessed 25 September 2018).

Bal, M. and Abatan, A. (2017), Developing Additive Manufacturing Laboratory to Support Instruction and Research in Engineering Technology, American Society for Engineering Education, Paper ID \#19554.

Biddix, P.J. (2009), "Writing research questions", available at: https://researchrundowns.com/intro/writing-research-questions/ (accessed 24 October 2018).

BuildProtos (2017), "3D printing in research and development”, available at: http://buildprotos.com/3dprinting-in-research/ (accessed 24 September 2018).

Burmeister, E. and Aitken, L.M. (2012), "Sample size: how many is enough? ", Australian Critical Care fournal, pp. 1-10, available at: https://doi.org/10.1016/j.aucc.2012.07.002

Colletti, R.C. (2016), "A study of positions available in additive manufacturing/3D printing and the education and skill requirements for these positions", Doctoral Thesis, Eastern Michigan University, MI.

Cummings, I.T., Bax, M.E., Fuller, I.J., Wachtor, A.J. and Bernardin, J.D. (2017), A Framework for Additive Manufacturing Process Monitoring $\mathcal{E}$ Control. Topics in Modal Analysis and Testing, Vol. 10, Springer.

Davies, S. (2017), "End of year report: exploring the need for education in additive manufacturing", available at: www. tctmagazine.com/3d-printing-news/end-of-year-report-educationadditive-manufacturing/ (accessed 24 October 2018).

Delice, A. (2010), "The sampling issues in quantitative research", Educational Sciences: Theory \& Practice, Vol. 10 No. 4, pp. 2001-2018, available at: https://files.eric.ed.gov/ fulltext/EJ919871.pdf

Deradjat, D. and Minshall, T. (2015), "Implementation of additive manufacturing technologies for mass customisation", Proceedings of International Association for Management of Technology IAMOT 2015 Conference, pp. 2079-2094.

Despeisse, M. and Minshall, T.H. (2017), "Skills and education for additive manufacturing: a review of emerging issues", APMS 2017: Advances in Production Management
Systems. The Path to Intelligent, Collaborative and Sustainable Manufacturing, Vol. 513, pp. 289-297.

Dickens, P., Reeves, P., and Hague, R. (2016), "Additive manufacturing education in the UK", available at: https:// sffsymposium.engr.utexas.edu/Manuscripts/2012/2012-01Dickens.pdf

Drakoulaki, A. (2017), “3D printing as learning activity in higher education: a case study in a robotics' prototyping course", University of Oslo, Oslo. [UiO: Master Dissertation]

Du Preez, W.B. and De Beer, D.J. (2015), "Implementing the South Africa additive manufacturing technology roadmap the role of an additive manufacturing centre of competence", The South African fournal of Industrial Engineering, Vol. 26 No. 2, pp. 85-92.

Du Preez, W., De Beer, D., Greyling, H., Prinsloo, F., Sciammarella, F., Trollip, N., Vermeulen, M., and Wohlers, T. (2016), A South African Additive Manufacturing Strategy, Department of Science and Technology.

Fisher, M.L. (1997), "What is the right supply chain for your product?", Harvard Business Review, Vol. 75, pp. 105-117.

Ford, S. and Despeisse, M. (2016), "Additive manufacturing and sustainability: an exploratory study of the advantages and challenges", Fournal of Cleaner Production, Vol. 137 No. 2016, pp. $1573-1587$.

Garth, W. (2016), “Additive manufacturing has huge potential in South Africa", available at: www.bdlive.co.za/business/ management/2016/08/31/additive-manufacturing-has-hugepotential-in-sa (accessed 31 August 2016).

Gatto, A., Bassoli, E., Denti, L., Luliano, L. and Minetola, P. (2015), "Multi-disciplinary approach in engineering education: learning with additive manufacturing and reverse engineering", Rapid Prototyping fournal, Vol. 21 No. 5, pp. 598-603.

Go, J. and Hart, A.J. (2016), "A framework for teaching the fundamental of additive manufacturing and enabling rapid innovation", Additive Manufacturing Fournal Manufacturing, Vol. 10, pp. 76-87, doi: 10.1016/j.addma.2016.03.001.

Handal, R. (2017), "An implementation framework for additive manufacturing in supply chains", fournal of Operations and Supply Chain Management, Vol. 10 No. 2, pp. 18-31.

Harvey, S. (2016), "Teaching additive manufacturing in a higher education setting", Proceeding of Australia Association for Engineering Education, AAEE 2016. Coffs Harbour, Australia, pp. 1-8.

Huang, Y., Leu, M.C., Mazumder, J. and Donmez, A. (2015), "Additive manufacturing: current state, future potential, gaps and needs, and recommendations", fournal of Manufacturing Science and Engineering, Vol. 137 No. 1, pp. 014001-014010.

Jürgen, G., Marina, W., and Stefan, P. (2013), Thinking Ahead the Future of Additive Manufacturing - Exploring the Research Landscape, Heinz Nixdorf Institute, University of Paderborn.

Krassenstein, E. (2014), "Why 3D printing needs to take off in schools around the world", available at: https://3dprint.com/ 27743/3d-printing-benefits-schools/ (accessed 24 October 2018).

Kunniger, D. (2015), "Diffusion of additive manufacturing in Gauteng South Africa", Dissertation - Masters, University of Pretori, Pretoria. 
Lenagh, A. (2012), “The importance of technology transfer", available at: www.unemed.com/blog/the-importance-oftechnology-transfer (accessed 18 September 2018).

Makerstation (2017), "Idea to product plus lab", available at: http://makerstation.co.za/i2plab/ (accessed 17 October 2018).

Martz, E. (2013), "Bewildering things statistician say: failure to reject the null hypothesis", available at: http://blog.minitab.com/ blog/understanding-statistics/things-statisticians-say-failureto-reject-the-null-hypothesis. (accessed 12 September 2018).

Mellor, S., Hao, L. and Zhang, D. (2013), "Additive manufacturing: a framework for implementation", International Fournal of Production Economics, Vol. 149, pp. 194-201, doi: 10.1016/j.ijpe.2013.07.008.

Mellor, S. (2014), “An implementation framework for additive manufacturing, UoE", PhD Thesis, University of Exeter, Exeter.

Miller, L.A., Lovler, R.L., and McIntire, S.A. (2012), Foundation of Psychological Testing: A Practical Approach, SAGE Publications, CA.

Minetola, P., Luliano, L., Bassoli, E. and Gatto, A. (2015), "Impact of additive manufacturing on engineering education - evidence from Italy", Rapid Prototyping fournal, Vol. 25 No. 5, pp. 535-555.

NSTF (National Science and Technology forum) (2016), "Discussion forum S.E.T for socio-economic growth. Lightbased technologies innovation forum - advances in light-based technologies in solar energy, additive manufacturing and fibre optic communications", available at: www.nstf.org.za/ discussion-forum/light-based-technologies-innovation-forum/

Nunnally, J. and Bernstein, L. (1994), Psychometric Theory, McGraw-Hill Higher, New York, NY.

Oberholzer, E. (2018), "Aeroswift: the biggest, state-of-the-art 3D printer in SA", available at: www.thesouthafrican.com/ aeroswift-biggest-3d-printer/. (accessed 5 August 2018).

Pallant, J. (2011), SPSS Survival Manual: A Step by Step Guide to Data Analysis Using SPSS, 4th ed., Allen \& Unwin, Australia.

Panesar, A., Brackett, D., Ashcroft, I., Wildman, R. and Hague, R. (2015), "Design framework for multifunctional additive manufacturing: placement and routing of threedimensional printed circuit volumes", fournal of Mechanical Design, Vol. 137 No. 11.

Peña, V. Lal, B. and Micali, M. (2015), "National science foundation's role in additive manufacturing", IDA Research Note, pp 59-60.

Piedmont, R.L. (2014), Inter-Item Correlations. Encyclopedia of Quality of Life and Well-Being Research, Springer, Netherlands, pp 3303-3304, doi:10.1007/978-94-0070753-5_1493.

Pradel, P., Zhu, Z., Bibb, R. and Moultrie, J. (2018), “A framework for mapping design for additive manufacturing knowledge for industrial and product design", fournal of Engineering Design, Vol. 29 No. 6, pp. 1-37.

Radharamanan, R. (2017), "Additive manufacturing in manufacturing education: new course development and implementation", American Society for Engineering Education, ASEE Annual Conference and Exposition paper, Paper ID \#20377., pp. 1-14.
RAPDASA (2018), “Additive manufacturing in South Africa”, available at: www.rapdasa.org/additive-manufacturing-insouth-africa/ (accessed 21 September 2018).

Reynaldo, J. and Santos, A. (1999), “Cronbach's alpha: a tool for assessing the reliability of scales", Fournal of Extension, Vol. 37 No. 2.

Roitenberg, J. (2016), "The intersection of STEM and 3D printing in higher Ed", available at: http://eschoolmedia. com/wp-content/uploads/2016/06/StratasysPOV1208.pdf. (accessed 18 September 2018).

Ruffo, M., Tuck, C. and Hague, R. (2006), "Cost estimation for rapid manufacturing-laser sintering production for low to medium volumes", Proceedings of the Institution of Mechanical Engineers, Part B: Fournal of Engineering and Management, Vol. 220 No. 9, pp. 1417-1427.

Scott, C. (2017), "South Africa's giant aeroswift 3D printer gearing up for commercial production", available at: https:// 3dprint.com/166672/south-africa-aeroswift-project/ (accessed 5 August 2018).

Serdar, T. (2016), "Educational challenges in design for additive manufacturing", American Society for Engineering Education, ASEE 123rd Annual Conference and Explosion New Orleans, Los Angelis, pp. 1-10.

Shaw, J. (2017), “3D printing education: learn to incorporate 3D printing in the class", available at: https://pinshape. com/blog/3d-printing-education-in-the-class/ (accessed 20 September 2018).

Swarup, S.R., Ishant, S. and Shivam, G. (2018), "Innovative training framework for additive manufacturing ecosystem to accelerate adoption of three-dimensional printing technologies", 3D Printing and Additive Manufacturing fournal, Vol. 5 No. 2.

Tess (2017), "Russia's skoltech opens state-of-the-art AM lab equipped with russia's largest metal 3D printer", available at: www.3ders.org/articles/20171130-russia-skoltech-opens-state-of -the-art-am-lab-equipped-with-russia-largest-metal-3dprinter.html (accessed 24 September 2018).

Thurn, L.K., Balc, N., Gebhardt, A. and Kessler, J. (2017), "Education packed in technology to promote innovations: teaching additive manufacturing based on a rolling lab", MATEC Web of Conferences, 137, 02013. MTeM - AMaTUC 2017, doi: 10.1051/matecconf/201713702013.

Tilton, B. Dobner, E. and Holdowsky, J. (2017), “3D opportunity for standards additive manufacturing measures up", available at: www2.deloitte.com/insights/us/en/focus/3d-opportunity/additivemanufacturing-standards-for-3d-printed-products.html (accesses 25 September 2018).

Togwe, T., Tanju, B. and Eveleigh, T. (2018), "Using a system engineering framework for additive manufacturing", System Engineering, pp. 1-10, doi: 10.1002/sys.21447.

Tuck, C. and Hague, R. (2006), "The pivotal role of rapid manufacturing in the production of cost-effective customised products", International fournal of Mass Customisation, Vol. 1 Nos 2/3, pp. 360-373.

Walter, M., Holmstrom, J., Tuomi, H. and Yrjolo, H. (2004), "Rapid manufacturing and its impact on supply chain management", Proceedings of the Logistics Research Network Annual Conference, pp. 9-10.

Waseem, K., Kazmi, H.A. and Qureshi, O.H. (2016), "Innovation in education - inclusion of 3D-printing 
technology in modern education system of Pakistan: case from pakistani educational institutes", Fournal of Education and Practice, Vol. 7 No. 36, pp. 1-8.ISSN 2222-1735.

Williams, C.B., Mistree, F. and Rosen, D.W. (2011), "A functional classification framework for the conceptual design of additive manufacturing technologies", fournal of Mechanical Design, Vol. 133 No. 12.

Williams, C.B. and Seepersad, C.C. (2012), "Design for additive manufacturing curriculum: a problem- and project-based approach", 23rd Annual International Solid Freeform Fabrication Symposium - An Additive Manufacturing Conference, SFF:8192, University of TX at Austin, pp. 81-92.

Williams, G. (2016), "Additive manufacturing has huge potential in South Africa", available at: www.bdlive.co.za/business/ management/2016/08/31/additive-manufacturinghas-hugepotential-in-sa (accessed 16 December 2017).

Wohlers Associates, Inc (2011), Additive Manufacturing Technology Roadmap for Australia - CSIRO, the Commonwealth Scientific and Industrial Research Organisation.

Wohlers, T. (2010), "State of the industry", Wohlers Annual Worldwide Progress Report, Wohlers Associates.

Wu, B., Myant, C. and Weider, S.Z. (2017), "The value of additive manufacturing: future opportunities. Institute of molecular science and engineering”, Imperial College London, Briefing Paper, No. 2.

Yeong, W.Y. and Chua, C.K. (2013), “A quality management framework for implementing additive manufacturing of medical devices", Virtual and Physical Prototyping, Vol. 8 No. 3, pp. 193-199, doi: 10.1080/17452759.2013.838053.

Zelinski, P. (2016), "Educators and industry discuss need for engineering education to adapt to AM", available at: www. additivemanufacturing.media/blog/post/educators-and-industry -discuss-need-for-engineering-education-to-adapt-to-am (accessed 3 May 2017).

\section{Further reading}

Cohen, L., Manion, L. and Morrison, K. (2000), Research Methods in Education, 5th ed., Routledge/Falmer, London.

Sullivan, P. and McCartney, H. (2017), "Integrating 3D printing into an early childhood teacher preparation course: reflections on practice", Fournal of Early Childhood Teacher Education, Vol. 38 No. 1, pp. 39-51.

\section{Corresponding author}

Micheal Omotayo Alabi can be contacted at: micalabs@ gmail.com 